\title{
De la guerra revolucionaria a la revolución democrática. El FMLN en El Salvador
}

Alberto Martín Áluarez ${ }^{1}$

Universidad de Colima

Traducción: Luis Alvarenga

Departamento de Filosofía

UCA, San Salvador

RESUMEN: En el presente trabajo, se reconstruye la historia del FMLN, a partir del surgimiento de las organizaciones político-militares en la década de 1970, que le darían origen en la década siguiente. El documento da cuenta de la transformación del frente guerrillero a partido político y hace un balance del legado social y político de la que fuera descrita como una de las guerrillas más exitosas en América Latina.

ABSTRACT: The following paper reconstructs the history of the FMLN, since the rise of the politico-militar organizations on the 1970's. This document provides an account of the transformation of the FMLN from a guerrilla front to a political party and also makes a balance of the socio-political legacy of one of the most successful guerrillas in Latin America. 


\section{El contexto histórico y el surgimiento de las organizaciones político-militares}

\subsection{Las raíces del conflicto}

Las causas principales del conflicto salvadoreño se encuentran, por una parte, en la persistencia, a lo largo del siglo XX de una estructura económica primario - exportadora fundada en la concentración de la tenencia de la tierra y de los ingresos en manos de una pequeña élite económica. Por la otra, dichas causas pueden rastrearse en la existencia de un régimen político autoritario y excluyente que estaba dedicado a defender los intereses de esa élite y que confrontó la amplia movilización popular acudiendo a una represión indiscriminada. La exclusión política y económica de la mayoría de la población ayudó a diseminar la ideología revolucionaria y al crecimiento de los grupos guerrilleros creados a principios de la década de 1970. Dada la falta de canales institucionales que podrían resolver la crisis política, económica y social que prevalecía en esa década, una gran parte de la sociedad salvadoreña vio en la lucha armada la única vía posible para enfrentar la violencia estructural.

\subsubsection{La crisis del modelo económico de exportaciones primarias}

Los cimientos económicos y sociales de El Salvador actual se establecieron durante el Ilamado "período liberal", comprendido entre 1881 a 1921. En ese momento histórico se fortaleció un modelo económico basado en el cultivo y la exportación de café, que se volvió la principal fuente de ingresos del país en la década de 1930. La adopción de este modelo económico de exportaciones primarias tuvo grandes repercusiones en los campos social y político. Provocó que la tenencia de la tierra cultivable - la cual era el principal recurso productivo del país y, por ende, su principal activo- se concentrara en grado sumo. Vale la pena afirmar que en 1970, mientras el $86 \%$ de la población que trabajaba en el agro recibía el $24 \%$ de los ingresos que se generaban, un $2 \%$ de la población recibía el $46 \%$ de los mismos (Gordon 1989: 33). La mayor parte de los ingresos estaban en manos de una pequeña y poderosa oligarquía terrateniente que ejercía un dominio casi completo sobre la economía y sociedad salvadoreñas a lo largo del siglo XX. Al otro lado del espectro se encontraban las masas campesinas que, marginadas de las áreas central y occidental del país dedicadas a la expansión cafetalera, buscaron resguardo en las áreas montañosas de las tierras agrícolas marginales localizadas en el norte del país. Obligadas a trabajar en terrenos de ínfimo rendimiento y sin suficientes ingresos para sobrevivir, se ofrecían para trabajar en 
las temporadas de corta de café. Es precisamente en este sector rural donde las organizaciones guerrilleras encontraron su mayor apoyo durante la década de 1980.

La modernización económica que tuvo lugar durante la segunda mitad del siglo $X X$, alimentada por un crecimiento de la demanda internacional, presentó una diversificación de los cultivos comerciales. La caña de azúcar y el algodón se sumaron al cultivo del café durante la década de 1950 y, por consiguiente, se monopolizaron las mejores tierras cultivables. En un país pequeño y sin una frontera agrícola que se pudiera expandir, el desarrollo de estos cultivos de exportación provocó un incremento en el arrendamiento de las tierras con vocación agrícola, que resultó en la expulsión de muchas familias campesinas, por cuanto no poseían tierra ni podían satisfacer las nuevas demandas. Como resultado de este proceso, el número de familias rurales desposeídas se triplicó prácticamente entre 1961 y 1971, y alcanzó casi el 30\% del total de familias del país, mientras que en 1971 casi el $64 \%$ de las familias poseía menos de una hectárea de tierra (Gordon 1989: 56).

La creación del Mercado Común Centroamericano en 1960 también trajo consigo un proceso limitado de industrialización por substitución de importaciones, que tuvo como resultado la expansión del comercio, la industria, la construcción y las finanzas. Bajo el cobijo de esta diversificación económi$\mathrm{ca}$, la estructura social salvadoreña sufrió grandes cambios durante este período. Hubo una migración rural significativa hacia las áreas urbanas, en especial, hacia la capital. Además, las clases medias experimentaron un crecimiento notable durante estos años, especialmente los maestros y los empleados del gobierno, como consecuencia del crecimiento del aparato estatal. Este crecimiento se vio reflejado también en el incremento espectacular de la población universitaria que llegó a ser de un $224 \%$ entre 1961 y 1971 (Gordon 1989: 49). Cuando comenzaron a surgir los grupos guerrilleros en 1970, la mayoría de sus líderes provenían, efectivamente, de las filas estudiantiles universitarias. ${ }^{2}$

La denominada "Guerra del fútbol"s que tuvo lugar entre $\mathrm{El}$ Salvador y Honduras en el verano de 1969 y la crisis económica internacional de 1973 provocaron una disminución de los salarios reales, un crecimiento acelerado de la inflación y altas tasas de desempleo en los sectores industrial y manufacturero. La guerra obligó a repatriarse a más de 130,000 trabajadores agrícolas salvadoreños que vivían en Honduras. Esto, a su vez, resultó en una disminución aún mayor de la tierra cultivable en un país con el $60 \%$ de población rural a mediados de la década de 1970. Por tanto, el porcentaje de las familias 
rurales sin tierra aumentó a $40 \%$ en 1975 y a casi $65 \%$ hacia 1980 (Almeida 2008: 114). Esta sucesión de problemas económicos alimentó el descontento entre los trabajadores rurales y urbanos. La exigencia de una reforma agraria y la implementación de medidas efectivas contra la inflación y el desempleo fueron las reivindicaciones principales del movimiento popular que surgió a finales de la década de 1970. Este movimiento era la expresión de una alianza entre organizaciones campesinas, obreras, estudiantiles y magisteriales. Tal como se afirmó anteriormente, muchos activistas del movimiento popular se unieron posteriormente a las organizaciones guerrilleras.

\subsubsection{La exclusión política}

Desde el punto de vista políti$\mathrm{CO}$, se instituyó en el país un régimen autoritario fundado en la alianza entre la oligarquía terrateniente y los militares. Estaba cimentado en la continuidad de un sistema de privilegios para la oligarquía por medio del uso de relaciones coercitivas de trabajo aseguradas por la Fuerza Armada y los cuerpos de seguridad. La piedra de toque de este pacto entre las élites económicas y estatales descansaba en la "bifurcación" del poder (Parkman 2006: 52). Los militares se convirtieron en la élite política durante casi cincuenta años, mientras que la oligarquía mantenía un control casi completo de las principales institu- ciones económicas del país. En una economía que dependía de la exportación del producto del trabajo intensivo agrícola, que se estableció por medio de métodos coercitivos, el recurso a la represión se volvió una necesidad estructural de los grandes productores, que competían con sus pares internacionales basándose en salarios bajos. Dadas estas premisas, el régimen político sufrió casi permanentemente de una falta de legitimidad popular, que lo forzó a encarar sistemáticamente a la oposición con el uso intensivo de la represión. Para enfrentar el peligro constante causado por el descontento social, la Fuerza Armada y los cuerpos de seguridad se hicieron cargo de la protección de la élite económica a cambio de dejar en sus manos las instituciones estatales (Stanley 1996). Este esquema de bifurcación del poder, establecido bajo la amenaza de la revuelta campesina de 1932, persistió más allá de las condiciones históricas concretas que lo hicieron surgir. A lo largo del siglo XX, el aparato represivo adquirió una autonomía considerable con respecto a la élite económica y los militares afianzaron una serie de privilegios que continuarían defendiendo a lo largo de este período.

Es necesario apuntar que desde mediados de la década de 1960, el régimen político echó mano de una fachada de democracia representativa, al adoptar un sistema electoral de representación proporcional. 
Este sistema permitió el surgimiento electoral del mayor partido de oposición, el Partido Demócrata Cristiano (PDC). No obstante, cuando el incremento del apoyo popular que experimentó el PDC amenazó con quitar del poder al partido de los militares, el Partido de Conciliación Nacional $(\mathrm{PCN})$, el régimen respondió con el fraude electoral a una escala masiva en 1972 y 1977. También contrarrestó las fuertes exigencias de reforma agraria y de democratización política provenientes del movimiento popular a mediados de la década de 1970, incrementando la represión. ${ }^{4}$ La reforma agraria amenazaba la base económica de la oligarquía terrateniente, mientras que la democratización ponía en riesgo los beneficios obtenidos por los militares como resultado de su control sobre el Estado. Aunque el régimen se había embarcado en la represión de los opositores políticos en las diferentes crisis que enfrentó -1944, 1960, 1961 y 1968- la represión había sido selectiva y fue implementada principalmente por medio del encarcelamiento y la tortura. No obstante, a partir de 1972, la represión ejercida por el régimen cambió tanto cualitativa como cuantitativamente. Se convirtió en una represión masiva y recurrió a diferentes mecanismos. A partir de este momento, las "desapariciones" se volvieron comunes. Solían Ilevarlas a cabo los escuadrones de la muerte, esto es, personal sin uniforme de los cuerpos de seguridad que actuaban bajo la dirección de los servicios de inteligencia. Como ejemplo de ello, de 1966 a 1972, el Socorro Jurídico Cristiano —una de las principales organizaciones de derechos humanos del paísregistró solamente un caso de desaparición forzada. Las cifras se elevaron vertiginosamente, sin embargo, y llegaron a cuarenta y ocho casos entre 1973 y 1976 y a 611 de 1977 a 1980 (Almeida 2008: 152). Este aumento de la represión erosionó grandemente la legitimidad del régimen político y contribuyó a radicalizar a los militantes del movimiento popular. Pasaron de hacer demandas específicas según los diferentes sectores productivos que representaban a identificarse masivamente con el proyecto revolucionario sostenido por los movimientos guerrilleros, a los cuales se unieron rápidamente hacia finales de la década de 1970. El fraude electoral en curso (1972-1977) era percibido por parte de los activistas de las guerrillas como la confirmación de que la democratización pacífica del régimen político era imposible. Esta creencia también jugó un papel en la percepción de que el proyecto alternativo encarnado en las organizaciones guerrilleras era el único viable.

\subsubsection{El auge de la contracultura revolucionaria}

El crecimiento de la población urbana y el aumento exponencial de los estudiantes universitarios, asociado al proceso de moderni- 
zación económica mencionado anteriormente tuvo lugar en una etapa histórica - finales de la década de 1960 e inicios de la década de 1970 - marcada por el auge de la contracultura revolucionaria que predominó en toda Latinoamérica. El triunfo de la revolución cubana era, a los ojos de miles de jóvenes latinoamericanos, un ejemplo exitoso de cambio sociopolítico a través de las armas. Para citar a Martí (2004: 110), "la victoria cubana trajo consigo un cambio en el repertorio cultural de la acción colectiva en América Latina". A partir de la revolución cubana, la creación de grupos guerrilleros y la resultante toma del poder por medio de la lucha armada se volvieron soluciones aceptables a los ojos de quienes intentaban definir cómo cambiar verdaderamente una realidad definida por la pobreza, la desigualdad y el autoritarismo político. La revolución cubana contribuyó a presentar la violencia como el medio para alcanzar las transformaciones sociales y políticas a los ojos de un número considerable de jóvenes. Como resultado de la influencia del ejemplo cubano, la revolución y la lucha armada se volvieron prácticamente un imperativo moral para miles de jóvenes salvadoreños. Paralelo a esto, la aceptación de la vía revolucionaria cubana también significaba el rechazo de las propuestas políticas orientadas hacia un camino gradual al socialismo - tal como lo defendía el Partido Comunista de El Salvador (PCS) - y de aquellos que se rebelaron en contra de la posibilidad de hacer reformas dentro de los márgenes del capitalismo, como era el caso del Partido Demócrata Cristiano (PDC).

Otro elemento que marcó la contracultura revolucionaria de aquel tiempo en El Salvador era el marxismo-leninismo. Sin embargo, in en oposición al marxismo de manual exportado por la Unión Soviética y divulgado por el PCS, el cual era la versión dominante de marxismo prevaleciente en las universidades (el suelo nutricio que produjo a la mayoría de fundadores de las organizaciones revolucionarias), a fines de la década de 1970, se difunde entre los estudiantes de la UES el denominado "marxismo occidental". Los trabajos de Antonio Gramsci, Herbert Marcuse o Louis Althusser particularmente y las lecturas de economistas alineados con el trotskismo como Ernest Mandel, así como las obras de Vladimir llich Lenin, el marxismo vietnamita de Truoung Chih o los pensamientos del Che Guevara fueron las fuentes de la versión heterodoxa de marxismo-leninismo que produjeron los primeros militantes de los grupos guerrilleros salvadoreños. ${ }^{5} \mathrm{~A}$ partir de estas influencias, los activistas extrajeron una serie de premisas básicas. En primer lugar, la falta de autonomía del Estado, al que se veía como una expresión de los intereses de la clase dominante, esto es, los de la oligarquía terrateniente. El rechazo a la democracia repre- 
sentativa, vista como una fachada para esconder el dominio oligárquico, lo que condujo a su vez al rechazo a las elecciones como un medio para obtener el poder. La creencia de que era imposible buscar la justicia social dentro del marco del capitalismo, que llevó a los activistas a criticar todas las estrategias de reforma, y a aspirar en cambio a la construcción de una sociedad socialista y a contemplar a la lucha armada como la única vía posible para llegar al poder. Por último, también existía la creencia acerca del papel necesario de una "vanguardia" de revolucionarios profesionales que desatarían la revolución, derrocarían al ejército del régimen y capturarían el aparato de Estado (Grenier 1999: 75).

El otro elemento principal del repertorio cultural en el cual los primeros militantes guerrilleros se socializaron políticamente fue la teología de la liberación. Los sacerdotes católicos inspirados en este movimiento buscaron acercarse a los miembros pobres y excluidos de sus sociedades, promoviendo un deseo activo de transformar su realidad e infundiendo una mirada crítica a las visiones fatalistas que habían caracterizado a dichos sectores durante siglos. En el caso salvadoreño, los líderes religiosos que siguieron la teología de la liberación la implementaron, principalmente, desarrollando estructuras asociativas entre las poblaciones rurales de las áreas más deprimidas del país: Las comunidades cristianas de base $y$ las asociaciones campesinas. Esta nueva interpretación del cristianismo también influyó en los sectores juveniles del PDC y de organizaciones juveniles de la iglesia católica. Muchos jóvenes que estaban afiliados a dichas organizaciones juveniles, tales como la Asociación Católica Universitaria Salvadoreña (ACUS), solían estar comprometidos en esfuerzos pastorales de la iglesia católica y estaban involucrados en apoyar las comunidades rurales a través de diversos medios, como las campañas de alfabetización que utilizaban el método del educador brasileño Paulo Freire. ${ }^{6}$ Estos esfuerzos hicieron posible que la juventud de clase media pudiera contemplar de primera mano la miseria en que vivían miles de trabajadores salvadoreños. Muchos de estos jóvenes, a los que se les habían inculcado profundas creencias religiosas, encontraron en las enseñanzas de la teología de la liberación una legitimación para luchar por una mejora en las condiciones de vida de los trabajadores agrícolas, inclusive con las armas en la mano, mientras que el marxismo-leninismo y el ejemplo cubano les proporcionaban las estrategias organizativas y los fines políticos últimos necesarios para esta lucha.

Debe decirse que el ambiente intelectual de la Universidad de El Salvador (UES) de finales de la década de 1960 estimuló la expansión de esa contracultura revolucionaria. 
Por un lado, los planes de estudio permitían que todos los estudiantes tuvieran acceso a materias de ciencias sociales -incluyendo a quienes provenían de las ciencias experimentales. Desde 1964, era obligatorio para los estudiantes de primer año inscribir materias del área de ciencias sociales _las Ilamadas "áreas comunes"-. Esto los puso en contacto con las ideas de los clásicos del marxismo, así como con los planteamientos de los teóricos académicos de la dependencia y de la teoría crítica latinoamericana, que constituían las perspectivas predominantes de la universidad en aquel tiempo. Esto se vio favorecido por el hecho de que la UES abrió sus puertas a profesores del Cono Sur, ${ }^{7}$ que ayudaron a difundir el marxismo y la teoría de la dependencia dentro del estudiantado. La universidad fue el escenario donde cientos de jóvenes salvadoreños fueron socializados políticamente. Las asociaciones estudiantiles fueron el foco de la difusión del pensamiento crítico y se constituyeron en espacios de micro - movilización, desde los cuales los estudiantes se ligaron al movimiento popular, especialmente a las luchas obreras y magisteriales de la segunda mitad de la década.

También es interesante notar que esta contracultura revolucionaria estimuló la adopción de un nuevo papel político para las mujeres en El Salvador. Aunque las reivindicaciones de género no eran parte del movimiento revolucionario, es notable que las mujeres salvadoreñas se incorporaron fuertemente a la lucha revolucionaria (hay cifras aproximadas, según las cuales, las mujeres eran el $30 \%$ de la fuerza del FMLN). Estas mujeres desarrollaron todo tipo de tareas dentro del movimiento y en muchos casos llegaron a posiciones de liderazgo dentro de las organizaciones. El Ejército Revolucionario del Pueblo (ERP) es, en este caso, el más representativo, puesto que en la composición de su Comisión Política durante la década de 1980, constituida por siete miembros, tres eran mujeres. El desarrollo del movimiento revolucionario constituyó la etapa inicial de la incorporación de las mujeres salvadoreñas a la lucha política.

\subsection{El comienzo de la lucha armada}

Los primeros dos grupos guerriIleros que se crearon en El Salvador en la década de 1970 fueron las Fuerzas Populares de Liberación "Farabundo Martí", FPL, fundada el primero de abril de 1970, y el ERP, fundado oficialmente el 2 de marzo de 1972.

\subsubsection{Las FPL}

En el caso de las FPL, sus padres fundadores fueron sindicalistas y universitarios que habían sido miembros del PCS. El hasta entonces Secretario General del PCS, Sal- 
vador Cayetano Carpio, promovió una escisión en el seno del partido en abril de 1970, que resultó en la creación de las FPL. Carpio argumentó que la estrategia del PCS de penetrar el movimiento sindical y de la lucha política pacífica había alcanzado su fin. Un factor que influyó en su cambio de postura fue la represión gubernamental de la huelga de maestros organizada por ANDES 21 de Junio. El sindicato de maestros convocó a la huelga en febrero de 1968 en respuesta a la reforma educativa llevada a cabo en la administración de Fidel Sánchez Hernández. Las movilizaciones a las que convocó ANDES 21 fueron apoyadas por los estudiantes universitarios a través de la AGEUS y por los estudiantes de secundaria, muchos de los cuales se volverían pronto líderes estudiantiles y fundadores de los grupos guerrilleros. La huelga de ANDES 21 fue reprimida cruelmente por parte de los cuerpos de seguridad. Como resultado de ello, dos trabajadores que pertenecían a la Federación Unitaria Sindical Salvadoreña (FUSS) del PCS, que habían apoyado la huelga, fueron asesinados, y al menos treinta dirigentes del movimiento fueron encarcelados. Pocos días más tarde, se encontraron los cadáveres mutilados de dos trabajadores asesinados. Esto jugó un papel importante en el cambio de las percepciones de los estudiantes y educadores sobre el Estado, y fue uno de los factores clave que condujo a los disidentes del PCS a romper con el partido y a dar curso a una práctica violenta de la política. Junto a esto, el impacto de la posición oficial del PCS ante la guerra de El Salvador y Honduras en 1969 debe mencionarse: El Comité Central del PCS apoyó al gobierno en este conflicto, mientras que el Secretario General y un pequeño sector crítico de la juventud del partido se opusieron.

A partir de su pequeño núcleo inicial, las FPL desarrollaron una estrategia de expansión en varios sectores sociales, en particular, dentro de la universidad, que empezó con una célula en la Facultad de Medicina. ${ }^{8} \mathrm{Al}$ principio, las FPL estaba dividida en dos comandos urbanos. Los miembros de cada comando tenían instrucciones de crear su propia red de quince miembros ${ }^{9}$ alrededor de su comando. Por medio de los nuevos activistas que se reclutaron en la universidad, las FPL también entraron en contacto con grupos socialcristianos y con la estructura de las comunidades de base organizadas por la iglesia católica, alineadas con la doctrina social de la iglesia católica que venía del Concilio Vaticano II y de la Conferencia Episcopal de Medellín.

Estas organizaciones promovieron una actitud de compromiso activo con la realidad y con la transformación de esta realidad por medio de la solidaridad y la educación liberadora. Por medio de los contactos que ciertos miembros de las FPL —que a la vez eran ac- 
tivistas de aquellas organizaciones vinculadas con la iglesia católicatuvieron con religiosos progresistas, las organizaciones guerrilleras se introdujeron en las comunidades de base del norte y centro del país, comenzando con el departamento de Chalatenango a fines de 1972 . La base de apoyo campesino en el norte de este departamento se compuso principalmente de campesinos que tenían pequeñas parcelas de tierra en lotes de bajo rendimiento, que solían trabajar en las temporadas de café en las plantaciones del occidente de El Salvador. Esta base rural, junto a la de los departamentos de Morazán y San Vicente, se volvió la más proclive a unirse a los grupos guerrilleras, convirtiendo así a dichos departamentos en bastiones de la insurgencia durante la década de 1980.

Los militantes de las FPL, por su parte, reprodujeron la estrategia de expansión que el PCS había implementado tradicionalmente en la universidad. Crearon grupos de estudio del marxismo y, después, sus propias asociaciones estudiantiles. En la universidad, los primeros activistas de esta organización guerrillera comenzaron sus grupos de estudio con el fin de reclutar a los estudiantes más radicalizados. Solían contactar a sus compañeros de clases, a sus amigos o conocidos y a aquellos con quienes habían estado activos durante las movilizaciones estudiantiles de $1968 .{ }^{10}$

\subsubsection{El ERP y sus cismas}

Con respecto al ERP, este fue el producto conjunto del flujo de al menos tres grupos diferentes de jóvenes, la mayoría de los cuales tenía una historia previa de militancia política. El primero de estos agrupamientos, conocido como "El Grupo", estaba compuesto principalmente de estudiantes universitarios de extracción socialcristiana. En su mayor parte habían formado parte o habían colaborado con asociaciones estudiantiles de la iglesia católica, como ACUS, o de raíz socialcristiana, como el Movimiento Estudiantil Social Cristiano (MESC). Algunos de sus miembros estuvieron implicados en el secuestro del famoso empresario Ernesto Regalado Dueñas, una acción fallida que contó con la colaboración de miembros de las Fuerzas Armadas Rebeldes (FAR) de Guatemala, y tras de la cual se recompusieron contactando a otros activistas estudiantiles. Un segundo grupo estaba formado por estudiantes universitarios que formaban parte de un grupúsculo armado denominado Comandos Organizadores del Pueblo. Algunos de entre estos últimos había militado en la Juventud Estudiantil Católica (JEC) siendo aún estudiantes de secundaria, y habían tenido un papel destacado más tarde como miembros del Comité de Representantes de Áreas Comunes (CRAC - Onomatopeya de Ruptura) en la Huelga de Áreas Comunes de 1970 
que tuvo lugar en la UES. Entre ellos estaban Joaquín Villalobos ${ }^{11}$ y Rafael Arce Zablah, dos activistas clave en el futuro desarrollo del ERP. Habían sido compañeros de clases en el Liceo Salvadoreño, un colegio católico prestigioso en El Salvador y trabajaron juntos en campañas de alfabetización en el campo. Como estudiantes de la UES y miembros de la ACUS, tomaron parte en la organización de movilizaciones estudiantiles en 1969 y se unieron al naciente ERP hacia 1970. Rafael Arce Zablah, como miembro del ERP y gracias a su proximidad con religiosos progresistas, conoció al padre Miguel Ventura en 1974. Ventura era párroco en el norte de Morazán e introdujo a Arce Zablah a las comunidades eclesiales de base que organizó en la región de Torola-Villa El Rosario-San Fernando (Binford 2004: 122). Esta región se volvió la zona de mayor desarrollo del ERP y fue su bastión durante la guerra civil. Después de la muerte de Zablah acaecida en 1975, su trabajo con las comunidades rurales del norte de Morazán fue continuado entre otros por un estudiante de filosofía Ilamado Juan Ramón Medrano ${ }^{12}$.

El tercer núcleo de activistas que crearon el ERP estaba compuesto de estudiantes de secundaria del Instituto Obrero Celestino Castro, muchos de los cuales también estaban afiliados a la Unión de Jóvenes Patriotas (UJP) del PCS ${ }^{13}$. Este instituto se creó en 1967 con financiamiento del Sindicato de Trabajadores Universitarios Salvadoreños (STUS), parte de la federación unitaria FUSS, que estaba controlada a su vez por el PCS. La finalidad del instituto era formar a los futuros dirigentes sindicales y tanto su administración como su planta de docentes ocupaba lugares importantes en el gremio magisterial ANDES 21 de Junio (Almeida 2008: 81). Entre otros, se encontraban Mario Medrano, ex secretario de dicho gremio, Emma Guadalupe Carpio, hija de Salvador Cayetano Carpio, padre fundador de las FPL, y Armando Herrera. ${ }^{14}$ Había células de la UJP en el instituto, que promovieron la participación estudiantil en las movilizaciones de 1968. De 1970 a 1972, algunos de estos activistas tomaron contacto con los militantes de "El Grupo" y se les unieron. Entre 1969 y 1970, estos activistas se separaron de la estrategia gradualista y de la participación electoral que apoyaba el PCS y se dedicaron a la creación de un grupo armado. La historia se repitió en este caso: la represión de 1968 y el desacuerdo con la estrategia del partido comunista, fueron elementos fundamentales en su decisión de iniciar la lucha armada.

La tercera organización armada que apareció en la década de 1970 fue el resultado de una escisión en el ERP. La RN se fundó en mayo de 1975, cuando un importante grupo de militantes del ERP reaccionaron contra el asesinato de dos de 
sus compañeros: Roque Dalton y Armando Arteaga. Ambos fueron acusados por parte de la dirigencia del ERP de poner en peligro la acumulación militar del ERP y de ser agentes de la CIA. En respuesta, un número considerable de militantes, entre ellos, Ernesto Jovel, Lil Milagro Ramírez y Eduardo Sancho dejaron el ERP y crearon la RN. Este núcleo de activistas provenía de un grupo que, cuando formaba parte del ERP, mantuvo un vínculo más fuerte con el movimiento popular, en particular con sectores sindicales y de la iglesia católica, los cuales, desde el comienzo, les proporcionaron una considerable base social.

El ERP también creó las bases sobre las cuales se erigió otro grupo guerrillero: el Partido Revolucionario de los Trabajadores Centroamericanos (PRTC). Los desacuerdos en el seno del ERP con relación al papel del partido y sus medios de combate llevaron a un grupo de activistas a dejar el ERP y a establecer la Organización Revolucionaria de Trabajadores (ORT), entre 1973 y 1974. En este grupo estaban Fabio Castillo Figueroa, rector de la Universidad de El Salvador entre 1963 y 1967, Francisco Jovel, María Marta Valladares, Mario López y Roberto Galeano, entre otros. ${ }^{15}$ Este grupo estableció el PRTC el 25 de enero de 1976. Debe mencionarse que desde su nacimiento y hasta octubre de 1980, este partido se creó como una estructura regional que también tenía presencia en Costa Rica, Honduras y Guatemala.

\subsubsection{EI PCS}

Finalmente, el PCS comenzó a discutir seriamente la posibilidad de militarizar sus estructuras en la reunión plenaria del Comité Central celebrada en abril de 1977, en un momento en que el régimen político había entrado en una fase de represión indiscriminada contra los opositores políticos. Asimismo, en marzo de ese año, el régimen había orquestado un descarado fraude electoral para evitar la victoria de la oposición. Los militantes interpretaron estos hechos como signos de que las posibilidades de un camino reformista se habían agotado. Sin embargo, la creación efectiva de una estructura armada no se dio sino hasta el VII Congreso del Partido, que se celebró en abril de 1979, cuando El Salvador ya se encontraba en medio de una situación insurreccional. De 1972 a 1979, los comunistas continuaron apoyando una estrategia de participación en elecciones por medio de su plataforma electoral: la Unión Democrática Nacionalista (UDN), por medio de la cual se sumaron a la Unión Nacional Opositora (UNO), una amplia coalición de partidos de oposición que enfrentó al partido de los militares entre 1972 a 1979. 


\section{Guerrilla urbana y lucha de masas (1974-1980)}

\subsection{Creando un nuevo actor político: Los frentes de masas}

Desde 1974, las distintas organizaciones guerrilleras salvadoreñas implementaron una estrategia de acercamiento hacia el movimiento popular, que tenía dos direcciones principales. Por una parte, buscaron infiltrar a sus propios militantes en las organizaciones sindicales, campesinas o estudiantiles ya existentes y a partir de ahí tomar control de las organizaciones ahora infiltradas. Su intención era que sus militantes fueran elegidos para ocupar posiciones de dirigencia dentro de esas organizaciones, a través de medios democráticos. Los grupos guerrilleros también crearon sus propias organizaciones. Por otra parte, desde 1974, las diferentes organizaciones guerrilleras decidieron crear comités coordinadores de organizaciones populares cuyo objetivo era articular y coordinar las luchas de las distintas organizaciones que se encontraban bajo su control. La idea en cierta medida a partir del conocimiento que se tenía de la experiencia de Vietnam, donde la formación de un frente amplio de liberación nacional fue la clave para unir a un conjunto diverso de sectores bajo la hegemonía de los revolucionarios. ${ }^{16}$ En buena medida, fue así cómo el Frente de Acción Popular Unificada (FAPU), el primer comité coordinador en aparecer, se creó en junio de 1974. El FAPU era una iniciativa en contra del alto costo de la vida que unió a organizaciones campesinas y estudiantiles controladas por $-\mathrm{O}$ bajo la influencia de- las organizaciones guerrilleras, junto a algunos sacerdotes católicos progresistas de la región de Suchitoto ${ }^{17}$. En la formación del FAPU, algunos activistas estudiantiles identificados con la tendencia de la Resistencia Nacional, que pertenecía entonces al ERP, jugaron un papel clave. Al contrario del FAPU, que unió brevemente a activistas del ERP, las FPL y el PCS, los comités coordinadores que aparecieron después fueron iniciativas de una sola organización guerrillera, con el propósito de construir estructuras de coordinación de las organizaciones populares bajo su control. A consecuencia de ello, surgió el Bloque Popular Revolucionario (BPR), promovido por las FPL en 1975, las Ligas Populares 28 de Febrero, del ERP, en 1977 y el Movimiento de Liberación Popular (MLP), del PRTC, en 1979.

El acercamiento entre el movimiento popular y los grupos guerriIleros tuvo lugar en el contexto de una escalada represiva por parte del régimen y el recurso al fraude electoral masivo en 1972 y 1977 , para evitar la victoria de una oposición política que ahora parecía unida en contra del partido de los militares. ${ }^{18}$ Esta regresión autoritaria dio pie a un proceso de escalada en las demandas del movimiento 
popular y a un cambio en el marco de interpretación de sus agravios. A su vez, esto llevó al surgimiento de una nueva identidad colectiva que ya no estaba orientada hacia las demandas de los distintos sectores productivos, sino hacia un cambio completo en el sistema político y económico. Por tanto, las demandas y expresiones de protesta de los sindicatos y las organizaciones estudiantiles y campesinas se volvieron más radicales como respuesta al cierre de los espacios políticos, lo que tuvo como resultado que las organizaciones guerrilleras se apropiaran de la infraestructura del movimiento popular (Almeida 2008).

Tras la aprobación del decreto de la Ley de defensa y garantía del orden público en 1977, aumentó el número de asesinatos, arrestos y desapariciones forzadas de sindicalistas, miembros de organizaciones campesinas y activistas de las organizaciones estudiantiles a manos de los cuerpos de seguridad y los paramilitares. De julio de 1977 a octubre de 1979, el Estado fue responsable del asesinato de 461 personas y de la desaparición forzada de 131. En 1980, el promedio de personas asesinadas al mes era cerca de mil y la tendencia se mantuvo de esta forma hasta 1982 (Almeida 2008: 151).

Pese a esta represión, los años de 1978 y 1979 estuvieron marcados por amplias acciones de protesta. Las organizaciones populares aumentaron las movilizaciones y la toma de ministerios para protestar contra la represión y demandar la democratización del régimen. Los grupos guerrilleros también intensificaron sus acciones armadas contra las fuerzas de seguridad, así como sus acciones de propaganda y de captación de fondos por medio de los secuestros.

\subsection{El golpe de octubre de 1979 y la convergencia del movimiento revolucionario}

El contexto político salvadoreño experimentó una marcada inflexión a partir del 15 de octubre de 1979, cuando tuvo lugar un golpe que puso final al régimen autoritario establecido en 1932. Desde entonces, una junta cívico-militar creó un gobierno con representantes del centro y centro-izquierda del espectro político, junto a militares progresistas y con el apoyo del PCS. El control sobre el ejército y sobre los cuerpos de seguridad siguió, no obstante, en las manos del ala militar que estaba a favor de reprimir el movimiento social y aniquilar a la guerrilla. Fue, de hecho, la falta de control sobre los militares y el aparato paramilitar lo que volvió al cuerpo gobernante de la junta incapaz de ponerle fin a la represión, la cual llegó a su cenit a partir de este momento. Debido a esto, los miembros civiles de la junta dejaron el gobierno a principios de enero de 1980 y se creó un nuevo poder ejecutivo con representantes del PDC y de la Fuerza Armada. 
A mediados de 1979, las fuerzas guerrilleras, con la mediación del gobierno cubano, iniciaron un diálogo con el fin de establecer una plataforma de coordinación conjunta. Como resultado de dichas negociaciones, el 17 de diciembre de 1979, el PCS, la RN y las FPL establecieron una nueva estructura de coordinación, la Coordinadora Político-Militar (CPM), que se hizo pública el 10 de enero de 1980. El día siguiente, las organizaciones multisectoriales del movimiento social controladas por los grupos guerrilleros anunciaron la creación de la Coordinadora Revolucionaria de Masas (CRM), con el objetivo de implementar una insurrección armada como forma de resolver la crisis por la que pasaba el régimen.

Después, a raíz del asesinato del arzobispo de San Salvador, Monseñor Óscar Arnulfo Romero, el 24 de marzo de 1980, y del aumento de la represión por parte de la Guardia Nacional y de los grupos paramilitares de ultraderecha, se hizo más fácil que la oposición de centroizquierda y los grupos guerrilleros convergieran bajo la hegemonía de estos últimos. Un producto de esta convergencia fue la creación del Frente Democrático Revolucionario (FDR), en abril de ese año. El FDR agrupaba, entre otros, a disidentes del PDC bajo la denominación de Movimiento Popular Social Cristiano (MPSC), con Rubén Zamora como su líder prominente; el socialdemócrata
Movimiento Nacional Revolucionario (MNR), dirigido por Guillermo Manuel Ungo; al Movimiento Independiente de Profesionales y Técnicos (MIPTES), encabezado por Enrique Álvarez Córdova, la jesuita Universidad Centroamericana (UCA) y la Universidad de El Salvador (UES), junto a las estructuras de coordinación del movimiento social controladas por la guerrilla. La Dirección Revolucionaria Unificada (DRU) se fundó el 22 de mayo de 1980, la cual aglutinó a las FPL, la RN, El ERP y el PCS. Finalmente, el 10 de octubre de 1980 y después de muchas dificultades, se creó el FMLN, al cual se incorporó el PRTC en diciembre de ese año.

A finales de 1980, el FMLN y el FDR establecieron una alianza estratégica que duraría a lo largo de la guerra. Esta alianza adoptó la Plataforma Programática del Gobierno Democrático Revolucionario. Se trataba de un programa político de consenso entre los grupos guerrilleros y sus pares socialdemócratas y socialcristianos representados por el FDR, y sus demandas eran, entre otras, la disolución del ejército y las fuerzas de seguridad; la reforma agraria; la disolución de los poderes estatales y la promulgación de una nueva constitución. Este programa no hacía referencia alguna al socialismo como proyecto político $y$, en términos generales, minimizaba las demandas previas de las organizaciones armadas. 
Aunque las declaraciones de los dirigentes revolucionarios parecían indicar lo contrario, las cinco organizaciones que formaron el FMLN estaban separadas por diferencias profundas. Pese al hecho de que las cinco agrupaciones guerrilleras se definían a sí mismas como marxista-leninistas, cada una de ellos tenían interpretaciones distintas de la realidad salvadoreña. Más aún, había una fuerte desconfianza entre las distintas organizaciones, en particular, entre el ERP y sus antiguos compañeros de la $\mathrm{RN}$. A la vez, estas organizaciones estaban muy recelosas del Partido Comunista, el cual veía al resto de agrupaciones guerrilleras como "aventureros pequeño-burgueses".

También había importantes matices desde la perspectiva estratégica y táctica, como por ejemplo, en la política de alianzas con las fuerzas no revolucionarios. Las $F P L$, y particularmente su dirigente, Cayetano Carpio, mantuvieron una posición de radical oposición contra cualquier acuerdo con los militares. Por el contrario, la RN mantuvo desde el principio una política de acercamiento con la Fuerza Armada con el fin de crear una alianza con los grupos guerrilleros, el movimiento social, la Democracia Cristiana y los militares progresistas, a fin de derrocar a los militares de línea dura cuyo centro de poder estaba en la Guardia Nacional y los cuerpos policiales. ${ }^{19} \mathrm{La}$ pérdida del control de las fuerzas de seguridad por parte del gobierno de la Junta Revolucionaria instalada e octubre de 1979 y la subsiguiente escalada de represión contra el movimiento popular estimuló el acercamiento de la $\mathrm{RN}$ hacia el resto de las organizaciones armadas y la llevaron a adoptar una estrategia de enfrentamiento abierto contra la Fuerza Armada. Y, lo último pero no con ello lo menor, todas las organizaciones pretendían representar la verdadera vanguardia revolucionaria y erigirse en los verdaderos intérpretes del marxismo-leninismo. Estos elementos impidieron la unificación de los cinco grupos guerrilleros durante la década de 1980 y explican por qué cada organización dentro del FMLN mantuvo sus propias estructuras militares, logísticas y de cadena de mando.

Pese a lo anterior, la creación del Frente implicó la creación de estructuras compartidas entre todas las organizaciones, tales como la Comandancia General, su órgano de dirección superior, o varias comisiones especializadas donde cada organización del FMLN estaba representada, como por ejemplo, las comisiones de finanzas, solidaridad y propaganda. Una de estas comisiones que merece mención aparte es la Comisión Político-Diplomática, constituida de representantes de las cinco organizaciones y del FDR, que monitoreaban las relaciones del FMLN con gobiernos y partidos políticos del extranjero. 
Hacia 1980, gracias a su inserción en el movimiento popular, las organizaciones guerrilleras habían pasado de ser pequeñas organizaciones urbanas con unos cuantos comandos a convertirse en un movimiento guerrillero suburbano $y$ rural. Sin embargo, desde un punto de vista militar, estas organizaciones eran débiles, sin lugar a dudas. Aunque tenían varios miles de activistas organizados, ${ }^{20}$ su adiestramiento y sus armas dejaban mucho qué desear.

\section{La guerra revolucionaria (1981-1990)}

Desde que se hizo evidente a finales de 1979 que el gobierno no tenía control sobre los sectores radicales de la extrema derecha, o sobre los servicios de inteligencia y seguridad, las organizaciones guerrilleras llegaron a la decisión de derrocar al gobierno, que era el producto de una alianza entre los militares y los sectores conservadores del PDC, encabezados por Napoleón Duarte como figura visible, y que descansaba en el apoyo de los Estados Unidos. La estrategia de los grupos guerrilleros era combinar la ofensiva militar con una huelga general e insurrección urbana. ${ }^{21}$ Con estas ideas en la mente, el 10 de enero de 1981 el FMLN lanzó una ofensiva "final" a nivel nacional con el objetivo de derrotar a la fuerza armada y tomar el poder. El Frente intentó hacerlo antes de que asumiera la presidencia de los Estados Unidos el candidato republicano Ronald Reagan, por cuanto los comandantes guerrilleros preveían que esto le acarrearía al gobierno salvadoreño un mayor apoyo por parte de Estados Unidos y que, eventualmente, Ilevaría a una ocupación estadounidense. El Frente tenía una fuerza de alrededor de 2,500 hombres, todos ellos, armados y entrenados (Menjívar 2008: 66). También había un número indefinido de milicianos que protegerían a la población local y participarían en acciones locales. La ofensiva se lanzó desde campamentos seguros en el área rural y dos tercios del país presenciaron una serie de choques severos. Sin embargo, la falta de armas y entrenamiento, así como la falta de coordinación entre las diferentes organizaciones, impidió que el FMLN alcanzara su meta estratégica. Además, la insurrección popular masiva que esperaban los grupos guerrilleros no tuvo lugar. La extremadamente severa represión que implementó el régimen tuvo un efecto desmovilizador entre la población. Una semana después del lanzamiento de la ofensiva, el FMLN comenzó una retirada estratégica.

A partir de ese momento, las organizaciones guerrilleras se retiraron a las zonas rurales del norte $y$ el nororiente del país, y el conflicto devino en una guerra civil a gran escala. La mayoría de los activistas 
del movimiento social que estaban colaborando con los grupos guerrilleros, se integraron a las columnas de las distintas organizaciones en el campo. Se definieron las zonas bajo control del FMLN, y los denominados "poderes populares" se comenzaron a desarrollar, con el objetivo de organizar la producción y la administración política en dichas zonas.

El FMLN dividió a El Salvador en cuatro frentes - cuatro frentes geográficos, y un quinto, a cargo de la diplomacia y las relaciones internacionales. ${ }^{22}$ Había presencia militar de casi todas las organizaciones en todos los frentes geográficos, con la excepción del frente occidental, que solo tenía fuerzas del ERP, las FPL y la RN. ${ }^{23}$

Las organizaciones del FMLN se dedicaron a la tarea de establecer o reforzar sus contactos con gobiernos y partidos políticos extranjeros, con el objetivo de intentar resolver los problemas logísticos, financieros y diplomáticos creados por una guerra larguísima. Pese a que cada uno de los grupos guerrilleros habían establecido, cada uno por su cuenta, contactos internacionales a lo largo de la década de 1970, la creación del FMLN implicó tener un mayor acceso a un nivel superior de recursos. A través de la mediación cubana y nicaragüense, ${ }^{24}$ pudieron acceder a apoyo traducido en armas, munición y logística de países tales como Vietnam, Checo- slovaquia o la República Democrática Alemana. Financieramente, el FMLN era bastante autónomo durante la guerra, por cuanto extrajo la mayor parte de sus recursos de la ayuda provista a través de la red de comités de solidaridad creados en Estados Unidos, México y Europa y, en menor grado, de secuestros e impuestos de guerra. Desde el punto de vista diplomático, el FMLN fue capaz, desde un primer momento, de cosechar un apoyo político considerable de parte de la Internacional Socialista y de sus partidos políticos miembros, especialmente, del Partido Socialista Francés. Esto se vio facilitado por el hecho de que el MNR, miembro del FDR y, por tanto, un aliado del FMLN, pertenecía a la Internacional Socialista. Guillermo Ungo, su dirigente, era un político renombrado que gozaba del respeto de los socialdemócratas alrededor del mundo, lo cual le granjeó al Frente una importante base de apoyo desde la cual extendió sus contactos internacionales. Un ejemplo de la capacidad diplomática que desarrolló el FMLN-FDR fue la Declaración Franco-Mexicana de agosto de 1981, en la cual ambos gobiernos reconocieron a la alianza del FMLN-FDR como una fuerza política representativa y la legitimaron de tal forma que podría desempeñar en el futuro un papel de liderazgo para encontrar una solución política a la crisis salvadoreña. Esta declaración constituyó una victoria diplomática para el FMLN y contribuyó al aislamiento político 
del gobierno salvadoreño, el cual, en aquel tiempo, estaba fuertemente desacreditado por las continuas denuncias de las masacras perpetradas por la Fuerza Armada y los cuerpos de seguridad.

\subsection{Resistir, crecer y avanzar (1981-1983)}

La estrategia militar del FMLN desde 1981 a 1983 fue la de "resistir, crecer y avanzar". Los insurgentes desalojaron a la Fuerza Armada de las zonas norte y noriental de El Salvador cercanas a la frontera hondureña y ahí construyeron su retaguardia. También iniciaron acciones de "sabotaje económico", así como acciones de comando contra instalaciones militares, incluyendo el asalto de la base aérea de Ilopango en enero de 1982, donde destruyeron la mayor parte de las aeronaves de la Fuerza Aérea Salvadoreña. También intentaron contrarrestar la estrategia política del gobierno, centrada en celebrar elecciones y en crear un nuevo marco institucional, con la intención de marginar políticamente a los revolucionarios. En ese sentido, el FMLN intentó sabotear las elecciones a la Asamblea Constituyente en marzo de 1982, pero solo tuvo éxito de forma parcial. Desde mediados de 1982 a finales de 1983, el Frente subió en lo que respecta a poder militar y controlaba, por lo menos, una cuarta parte del territorio del país. Tenía ahora una fuerza de 10,000 a 12,000 hombres (Byrne 1996:
84). El desarrollo militar de las organizaciones guerrilleras superó a la acción política en la estrategia de los revolucionarios durante este período, aunque la segunda nunca desapareció del todo, como veremos más adelante. El Frente tenía la capacidad de construir unidades militares del tamaño de una brigada $(1,500$ hombres) y tenía dos brigadas: la Brigada Rafael Arce Zablah (BRAZ) del ERP y la Agrupación de Batallones Felipe Peña Mendoza, de las FPL. Con esta capacidad para concentrar tropas y armas, los guerrilleros pusieron a la fuerza armada en una situación crítica en 1983. Durante este año, la iniciativa de la guerra favorecía claramente al FMLN. Su fuerza se hizo manifiesta en el hecho de que tomó un número importante de pueblos y pequeñas ciudades - tales como Berlín, en el departamento de Usulután-y bastiones militares, como el cuartel de la IV Brigada de Infantería en El Paraíso, en el departamento de Chalatenango.

A la luz de esta situación, las Fuerzas Armadas salvadoreñas empezaron a desarrollar una estrategia centrada en el entrenamiento de pequeñas unidades, como los batallones de reacción inmediata, los cuales tenían la capacidad de penetrar las zonas controladas por el FMLN. Los militares también desarrollaron planes de acción cívica, que comprendían la construcción de escuelas, la pavimentación de caminos y la provisión de servicios 
de salud en las zonas donde se estaban expandiendo los grupos guerrilleros, los cuales eran de un alto valor estratégico y económico, como los departamentos de San Vicente y Usulután. En enero de 1983, el ejército implementó el Plan CONARA (Comité Nacional de Reconstrucción de Áreas) el cual, junto a todo lo anterior, también comprendió la organización de unidades paramilitares de defensa civil (Byrne: 1996: 86). Pese a una disminución inicial en la actividad del FMLN en San Vicente, el CONARA falló a finales de 1983, dada la incapacidad de la fuerza armada de separar a un importante contingente de sus fuerzas del combate. Este fue un momento de clara superioridad de los grupos guerrilleros.

Sin embargo, la estrategia consistente en una marcada concentración de fuerzas desarrollada por el FMLN también mostró serias limitaciones. Por un lado, los grandes contingentes guerrilleros eran altamente vulnerables a las incursiones aéreas y a la penetración por parte de la Fuerza Armada y, por el otro lado, exigían un nivel de recursos financieros y logísticos que se revelaba insostenible. Además, la continua necesidad de reclutar nuevos militantes llevó a algunas organizaciones del FMLN a implementar el reclutamiento forzoso, el cual resultó en un alto grado de deserciones, en la pérdida de apoyo en las zonas rurales donde se llevó a cabo esta práctica y en desgaste de la imagen internacional que presentaban (Byrne 1996: 105).

Por otra parte, la estrategia política de los revolucionarios durante este período estuvo sujeta a prioridades de orden militar. EI FMLN estaba convencido de que podía ganar la guerra, con lo cual, los contactos que mantenía con el gobierno eran de naturaleza táctica. Como se verá más adelante, desde mediados de 1981 a mediados de 1983, algunos dirigentes guerrilleros se opusieron rotundamente a cualquier tipo de negociación estratégica, en particular, en las filas de las FPL. Con respecto al gobierno salvadoreño y a la administración norteamericana, que se había convertido en un actor interno del conflicto, estos se oponían a negociar con los insurgentes durante este período y, por el contrario, hicieron de la derrota de los grupos guerrilleros su prioridad. Su estrategia a largo plazo era crear un nuevo régimen político que pudiera celebrar de forma periódica elecciones "demostrativas", las cuales darían una apariencia de normalización democrática, así como implementar una serie de reformas que pudieran restarle apoyo social al movimiento insurgente (siendo la reforma agraria la primera de estas reformas). Esto les permitiría Ilegar ante el Congreso de los Estados Unidos y justificar la financiación del esfuerzo militar, lo cual era su prioridad indiscutible. 


\subsection{Un "mar de guerrillas y de pueblo organizado" (1984-1989)}

La obvia incapacidad del FMLN para derrotar a la Fuerza Armada llevó a un cambio de estrategia. El estilo bélico desarrollado hasta 1983 había hecho un exclusivo hincapié en la creación de un gran contingente militar, a través de la militarización de todos los recursos humanos de la insurgencia. Los revolucionarios habían buscado una derrota estrictamente militar del gobierno, dejando a un lado la necesidad del trabajo político con la población de las ciudades, en las cuales, al fin de cuentas, se afincaría la guerra. Desde 1984, el objetivo principal ya no era vencer al ejército gubernamental en batallas decisivas a corto plazo, sino en lugar de ello, sumirlo en una guerra de desgaste —una estrategia más cercana a las intenciones originales de las FPL. El FMLN hizo énfasis en la combinación de la lucha armada con la lucha política de las masas para debilitar al gobierno y lanzar una contraofensiva de gran magnitud que se complementaria en el momento preciso con una insurrección popular (FMLN 1986). Con esta perspectiva en mente, el FMLN dispersó sus fuerzas a través del territorio salvadoreño, dividiéndolas en unidades pequeñas con suficiente capacidad de comunicación y movilización para concentrarlas rápidamente cuando fuera necesario, lo cual le permitió lanzar acciones de cierta magnitud. Junto a esto, también intensificaron sus acciones de sabotaje económico, emboscadas, ataques de francotiradores y el uso de minas terrestres. Asimismo, empezaron a reconstruir el movimiento popular en las ciudades donde había sido prácticamente desmantelado en 1981. Como resultado de todo lo anterior, el FMLN fue capaz de llevar la guerra a diez de los catorce departamentos del país y evitó que las autoridades locales se establecieran en casi la mitad de los municipios a fines de la década de 1980.

El giro hacia la organización política de las masas se volvió la prioridad del FMLN en este período. En ese sentido, el desarrollo de poderes duales en las áreas bajo control de los grupos guerrilleros y en las zonas en disputa contra la Fuerza Armada se volvió una parte central del control político en estos sectores. La idea era crear estructuras legales que estaban desconectadas formalmente de las organizaciones guerrilleras, y las que incluso utilizarían recursos gubernamentales. Serían, además, capaces de mantener una estructura de apoyo clandestino para los revolucionarios. Los grupos guerrilleros hicieron un gran esfuerzo para obstruir el establecimiento de las patrullas de defensa civil — grupos paramilitares organizados por la Fuerza Armada - y para frenar el trabajo en curso de las administraciones locales y judiciales en los 
lugares donde el gobierno no tenía control militar directo del territorio. En este sentido, Ilevaron a cabo secuestros y ejecuciones de alcaldes y funcionarios administrativos que fueron identificados como agentes del aparato represivo del gobierno, dada su capacidad de parar la organización popular autónoma. ${ }^{25}$

Finalmente, el Frente tomó ventaja del malestar que provocó en los sectores de menores ingresos la crisis económica que sacudió el país a mediados de la década de 1980. En 1984, comenzó una serie de huelgas contra el congelamiento de los salarios y la pérdida del poder adquisitivo, las cuales durarían hasta 1986. Según Byrne (1996: 143), los salarios industriales en 1987 eran el $51 \%$ de los salarios vigentes en 1980, mientras que la producción agrícola experimentó un decremento del $32 \%$ de 1980 a 1989. En este renacimiento de las protestas, los insurgentes vieron una oportunidad para radicalizar el movimiento popular, el cual, debidamente orientado por el FMLN, podría llevar a una insurrección que sería apoyada por una ofensiva de la insurgencia a nivel nacional.

Pese a estos desarrollos y a los esfuerzos organizativos que desplegaron las organizaciones guerrilleras, desde un punto de vista militar la situación apuntaba a una estabilización del conflicto y a un punto muerto en el cual ninguna de las dos partes tenían posibilidades reales para ganar la guerra, al menos, a mediano plazo. La victoria electoral del candidato democristiano Napoleón Duarte en 1984 representó una victoria política para la estrategia concebida por los Estados Unidos. La sucesión de los procesos electorales a lo largo de la década y la ausencia de acciones militares significativas en áreas urbanas por parte del FMLN, amenazaban con marginar políticamente a los insurgentes. El Frente necesitaba cambiar la dirección que estaba tomando la guerra si quería evitar perderla en el terreno político. Fue, de hecho, esta necesidad de cambiar la correlación de fuerzas desde un punto de vista político y militar lo que llevó a los insurgentes a desatar una ofensiva de gran escala en noviembre de 1989. Su objetivo era forzar al nuevo gobierno de la conservadora Alianza Republicana Nacionalista (ARENA) a comenzar un proceso sustancial de negociaciones con el FMLN. Algunos comandantes guerrilleros tenían, ciertamente, la esperanza de que la ofensiva podría desatar una insurrección popular que derrocaría al régimen (Lungo 1996: 18). La acción se venía preparando intensamente desde finales de 1988, pero lo que la precipitó fue el bombardeo de la sede de la Federación Nacional Sindical de Trabajadores Salvadoreños (FENASTRAS) a finales de octubre de 1989. San Salvador fue el principal escenario de la ofensiva, en la cual el FMLN introdujo a más de 2,000 combatientes, que permane- 
cieron en el lugar durante catorce días. Sin embargo, los bombardeos indiscriminados contra los barrios populares donde las organizaciones guerrilleras tenían fuerzas $y$, sobre todo, el convencimiento de que la población no se estaba alzando en masa para apoyar a los insurgentes, llevaron al Frente a hacer una retirada ordenada hacia las zonas que controlaba.

En la ofensiva fueron asesinados por lo menos mil civiles y cientos de ellos huyeron de las incursiones aéreas y del fuego cruzado. Además, el 16 de noviembre, cinco días después del comienzo de las operaciones militares, fueron asesinados seis sacerdotes jesuitas, así como dos de sus colaboradoras, en la UCA. Entre ellos, estaba el rector de la universidad, Ignacio Ellacuría, y los sacerdotes Segundo Montes e Ignacio Martín Baró, intelectuales de renombre internacional. Estos asesinatos fueron ordenados por el alto mando de la Fuerza Armada, conducido por el coronel René Emilio Ponce.

El resultado de la ofensiva de noviembre y los crímenes de la UCA ayudaron a crear las condiciones necesarias para el final negociado de la guerra. Por un lado, los sectores más recalcitrantes del gobernante partido ARENA estaban convencidos de que el FMLN tenía suficiente fuerza militar para continuar llevando a cabo la guerra durante un largo período de tiem- po. Además, la falta de respuesta por parte de la población por la cual no hubo un apoyo masivo a los insurgentes demostró que no se encontraban en situación de insurgencia y que el apoyo popular para el Frente no era tan grande como esperaban algunos comandantes guerrilleros. Pese a que durante los primeros días algunos centenares de personas que vivían en el cinturón obrero de San Salvador se sumaron a los grupos guerrilleros, su respuesta no fue masiva. El asesinato de los sacerdotes jesuitas, por su parte, llevó a cuestionar la política norteamericana hacia El Salvador dentro del Congreso estadounidense. Desde ese momento, la ayuda militar se volvió una herramienta de presión para obligar a los militares salvadoreños a aceptar una negociación con el FMLN.

\subsection{La negociación armada (1990-1991)}

Desde 1990 hasta finales de 1991, la lucha armada del FMLN ejerció presión sobre el gobierno para alcanzar una negociación en los mejores términos posibles. Ambas partes accedieron a comenzar las negociaciones con la mediación de las Naciones Unidas, el 4 de abril de 1990. Esta mediación contaba con el apoyo de los Estados Unidos, cuya aquiescencia pidió la ONU en diciembre de 1989. Además, las negociaciones estaban respaldadas por el Ilamado "Grupo de amigos del Secretario General", 
compuesto por los gobiernos de Colombia, México, Venezuela y España. Este primer acuerdo fue el pilar sobre el cual se basaron las negociaciones ulteriores. En mayo de 1990, las partes se reunieron en Caracas y convinieron una agenda de negociación dividida en dos partes. La primera comprendía una serie de acuerdos políticos en diferentes áreas, que crearían las condiciones necesarias para un cese del fuego: la Fuerza Armada, los derechos humanos, los sistemas electorales y judiciales, las reformas constitucionales, los temas socio-económicos y la verificación de los acuerdos por parte de las Naciones Unidas. Una vez declarado el cese al fuego, comenzaría una segunda fase de las negociaciones en la cual se abordarían los mismos temas con el objetivo último de establecer una serie de garantías para reintegrar a los miembros del FMLN a la política y la sociedad salvadoreña (Levine 1997: 223). El Frente creó una comisión negociadora que estaba compuesta por los cinco miembros de la Comandancia General: Schafik Handal (PCS), Leonel González (FPL), Francisco Jovel (PRTC), Joaquín Villalobos (ERP) y Eduardo Sancho $(R N)$, así como miembros de las comisiones políticas de las cinco organizaciones del Frente: Salvador Samayoa (FPL), Ana Guadalupe Martínez (ERP), Roberto Cañas (RN), Nidia Díaz (PRTC) y Dagoberto Gutiérrez (PCS).

El 26 de julio de 1990, las partes se reunieron nuevamente en
San José de Costa Rica y después de varios días, alcanzaron el acuerdo de no llevar a cabo acciones que pudieran contravenir los tratados de derechos humanos. Lo que más adelante se convertiría en el Acuerdo de San José fue el primer compromiso importante que se alcanzó en el marco de las negociaciones. A partir de ese momento, el Secretario General de Naciones Unidas desempeñó un papel clave para emprender una misión de verificación de los acuerdos y para proponer que se hicieran cambios a la agenda que se negoció en Caracas. El primer tema de esta agenda fue la discusión del papel de la Fuerza Armada, el cual se convirtió de inmediato en uno de los mayores obstáculos en la negociación. Hasta ese momento, el FMLN había insistido en la desaparición del ejército y en la disolución de los batallones de reacción inmediata y de los organismos de inteligencia, así como en la persecución de oficiales responsables de violaciones particularmente graves a los derechos humanos - todo lo cual fue rechazado por parte de los militares y el gobierno. Por lo cual, la ONU hizo arreglos para que el primer tema a discutirse en la mesa fuera el del respeto a los derechos humanos y que los asuntos más controversiales se discutieran en una fecha posterior, una vez que se hubiera establecido un clima de confianza entre las partes. Pese a este éxito inicial, las negociaciones Ilegaron a un punto muerto en enero de 
1991, después de que el FMLN derribara un helicóptero de combate que transportaba a un grupo de asesores militares norteamericanos que fueron capturados y luego ejecutados. ${ }^{26}$ Una vez que se superó este obstáculo, las pláticas de paz continuaron en México, en abril de ese año. En esta ronda de diálogo los temas que se discutieron simultáneamente fueron las reformas a la Fuerza Armada, las reformas constitucionales y los términos del cese al fuego (Samayoa 2003: 148). Las negociaciones se llevaron a cabo bajo la presión de que las reformas constitucionales que se negociarían tendrían que aprobarse antes del fin del mandato de la Asamblea Legislativa salvadoreña. La constitución del país requería que cualquier enmienda constitucional se aprobara en dos legislaturas consecutivas. Por tanto, si este proceso no se completaba en abril de 1991, los negociadores tendrían que esperar dos años hasta que el nuevo poder legislativo se renovara parcialmente. El 27 de abril, las partes negociadoras firmaron el Acuerdo de México, el cual fue el segundo compromiso más importante de las negociaciones. Este acuerdo contempló la reforma del ejército -el FMLN abandonó la exigencia de disolución de la Fuerza Armada-, junto a la creación de una fuerza policial nacional civil que sería independiente de los militares. Otra serie de reformas que fueron convenidas incluyeron la reforma del sistema electoral, los derechos humanos -incluyendo la figura del Procurador y el establecimiento de una Comisión de la Verdad que investigaría las violaciones más serias que tuvieron lugar durante la guerra- así como las reformas al sistema judicial, entre las cuales figuraba una reestructuración de la Corte Suprema de Justicia y, por último, una serie de reformas constitucionales.

El 26 de julio de 1991, se desplegaron los primeros elementos de la Misión de Observadores de Naciones Unidas en El Salvador (ONUSAL). Sin embargo, la presión de las Naciones Unidas y el Grupo de Amigos era necesaria para desbloquear las negociaciones, por cuanto ninguna de las partes quería hacer concesiones ulteriores en la mesa de negociaciones sin la implementación de un cese al fuego. Hasta ese momento, ambas partes buscaron ganar posiciones por medio de la presión militar. A fin de avanzar en el proceso de negociación, se creó una comisión ad hoc, que alcanzó acuerdos para purgar a los altos mandes militares que estaban involucrados en violaciones a los derechos humanos y para asegurar la participación del FMLN en la futura Policía Nacional Civil (PNC), a cambio de que los grupos guerrilleros desistieran en su demanda de formar parte de la Fuerza Armada. Dado que las preocupaciones del FMLN se vieron satisfechas con respecto a la desmilitarización y la impunidad de la Fuerza Armada, se sostuvo una nueva ronda 
de negociaciones en Nueva York, donde se firmó un nuevo acuerdo el 25 de septiembre de 1991. Los acuerdos básicos que se tomaron en Nueva York estaban relacionados con el futuro del ejército, su depuración y su reducción, su nueva doctrina y su formación. Se acordó la disolución de las fuerzas de las Policías Nacional y de Hacienda y de la Guardia Nacional, que se reemplazarían por una única fuerza policial -que estaría compuesta en un $20 \%$ por combatientes del FMLN. Se discutieron los asuntos concernientes a la agenda económica, incluyendo la distribución de la tenencia de tierra y la Comisión Nacional para la Consolidación de la Paz (COPAZ) ${ }^{27}$ se creó como una organización cuyo mandato fue el de supervisar el seguimiento de los acuerdos. Después de este primer Acuerdo de Nueva York, el FMLN anunció un cese de fuego unilateral. Las negociaciones continuaron en diciembre, para discutir algunos temas sensibles, como la reducción de la Fuerza Armada y la transferencia de la propiedad de tierras a los ex combatientes del FMLN, así como las garantías que tendrían los miembros del FMLN para poder reincorporarse a la vida civil. Finalmente, el 31 de diciembre de 1991, se firmó el segundo Acuerdo de Nueva York, que le puso fin a una guerra que había durado casi doce años. El 16 de enero de 1992, se celebró una ceremonia con motivo de la firma de los Acuerdos de Paz en el Castillo de Chapultepec, México. Un total de 15,007 militantes del FMLN (incluyendo tanto a combatientes como a "políticos"), se desmovilizaron entre julio y diciembre de 1992.

\section{Factores de la transición a la paz}

Desde el principio, el FMLN mantuvo una estrategia política y militar. No obstante, como se mencionó anteriormente, de 1980 a 1983 el Frente priorizó los aspectos militares en su estrategia y los supeditó a la lucha política. Desde finales de 1983, se desvaneció la esperanza de una pronta derrota del gobierno, lo cual, sumado a una serie de cambios internos, le permitió al Frente comenzar a promover una estrategia de negociaciones y lucha armada. Al final, después de la ofensiva de 1989, los grupos guerrilleros mantuvieron la presión militar como una forma para lograr mejores condiciones en la mesa de negociaciones. Esta sección proporciona un análisis de los factores internos (intrapartidarios) y externos (sociales, nacionales e internacionales) que arrojan luz sobre el cambio gradual del Frente en lo relacionado a su postura acerca del uso de la violencia. 


\subsection{Factores externos}

\subsubsection{Liberalización del régimen político}

La nueva alianza política que tomó el poder en 1981, y que gobernaría los destinos de El Salvador hasta 1989, fue responsable de implementar un proyecto de reformas que tuvo dos objetivos principales: la derrota militar del FMLN y la implementación de un programa para la reforma económica y política. Esta última tuvo la intención, tanto de privar a la insurgencia de su base de apoyo social como de minar la base económica del poder de la oligarquía terrateniente. Los elementos centrales de este proyecto reformista fueron los de realizar una reforma agraria en el área económica y establecer una poliarquía en el área política. No obstante, la coexistencia de esta última junto al objetivo de propinarle una derrota militar a la insurgencia en el contexto de la guerra civil, resultó en el hecho de que, a lo largo de la década de 1980 y, dada la persistencia de los militares y de la clase alta como actores políticos clave, el régimen salvadoreño fuera un caso de hibridación entre un régimen militar colegiado y una democracia electoral (Wickham-Crowley 1992). Pese a esto, la liberalización gradual del régimen a lo largo de la década, resultó en una apertura limitada del sistema político, así como en la celebración periódica de elecciones. ${ }^{28}$ Pese a su marcado propósito de contrainsurgencia, y pese al hecho de que las elecciones buscaban fundamentalmente un efecto demostrativo, esto es, probarle a la opinión pública que El Salvador estaba marchando bien en su camino hacia la democracia, los procesos electorales celebrados en la década de 1980 sirvieron para legitimar el nuevo marco institucional que surgió del golpe de 1979, y para debilitar políticamente al FMLN. El Frente no pudo ganar el apoyo de importantes sectores que se convirtieron en las bases que sostuvieron al gobierno del PDC y más tarde al de ARENA. Además, algunos sectores, en particular, los de clase media, retiraron paulatinamente su apoyo a la insurgencia en cuanto se desvanecieron sus posibilidades de victoria y el régimen mostró signos de apertura.

Particularmente, a principios de 1980, el PDC fue la organización que de forma más directa le disputó al FMLN el apoyo popular, por medio de las medidas reformistas que implementó durante el período en que encabezó el gobierno. Estas reformas se vieron acompañadas de la creación de organizaciones sindicales entre los beneficiarios de sus políticas, especialmente, de la reforma agraria. Estas organizaciones crearon las bases de apoyo que necesitaba el modelo reformista implementado por el PDC, contribuyendo de esta manera a su legitimación.

La apertura en el sistema político tuvo también repercusiones en 
la reducción relativa de la represión en las ciudades. Según Brockett (2005: 235), las muertes de civiles que fueron resultado de la represión disminuyeron considerablemente entre 1984 y 1988 . Mientras más de 18,000 personas fueron asesinadas por el ejército y los cuerpos de seguridad en 1981, el número anual de muertes descendió a 6,000 entre 1982 y 1983 y a menos de 4,000 en 1984. Llegando a menos de 2,000 en 1989. Lo mismo puede decirse con respecto a las cifras de personas desaparecidas. De 1,117 personas desparecidas en 1982, la cifra cayó a 526 en 1983 y a cerca de 200 en 1984. A partir de ahí, se redujeron a entre 200 y 300 al año durante el transcurso de la guerra.

La disminución en la represión desde mediados de 1980, junto a algunas garantías otorgadas a los procesos electorales, tales como el efecto de la presión internacional en general y del proceso de Esquipulas ${ }^{229}$ en particular, ofrecieron la posibilidad de iniciar una lucha política legal a los aliados civiles de la guerrilla. A fines de 1987, el FDR decidió volver a El Salvador e insertarse en el sistema político, participando en las elecciones de marzo de 1989 bajo la fórmula del partido Convergencia Democrática (CD). Su presencia le permitió al FDR probar que había garantías para defender sus propuestas de forma pacífica. La mayor transparencia de los procesos electorales, la inserción del FDR en el sistema político y el creciente po- der político de los partidos ayudó a presentar la vía electoral como algo creíble ante los ojos de las organizaciones armadas.

\subsubsection{Cambios en la élite económica}

La élite terrateniente salvadoreña se transformó profundamente durante la guerra, tanto en el plano económico como en el político.

La guerra civil produjo una crisis aguda en la agricultura de exportación, la cual había sido la base económica tradicional de la élite salvadoreña. Las reformas estructurales Ilevadas a cabo, esto es, la reforma agraria y la nacionalización de la banca y del comercio exterior, minaron los pilares del modelo agroexportador sobre los cuales había descansado la economía salvadoreña $y$, por consiguiente, el dominio de la élite económica. Pese a las grandes dificultades que se enfrentaron para aplicar la reforma y, aunque su radio de aplicación fue limitado, ésta afectó fuertemente a las bases de la economía de la élite, en particular, a lo concerniente a la producción de café. Según Cardenal (2002: 8), los 136 caficultores más fuertes se vieron afectados por la reforma. Entre ellos, estaban los ocho grupos familiares que habían monopolizado la mayoría de la producción. Junto a la reforma, el impacto de la guerra hizo que 88,000 hectáreas se vieran abandonadas — cerca del $43 \%$ de la tierra con vocación 
agrícola del país-. Esto, así como la desaparición de la infraestructura y el impuesto exigido por los grupos guerrilleros, contribuyeron a disminuir las ganancias de los productores. Por consiguiente, tanto la guerra como la reforma agraria causaron un impacto fuerte en la estructura de tenencia de la tierra, minando las bases económicas de la oligarquía. Además de esto, la nacionalización del comercio exterior, cuyo objetivo fue, entre otros, procurarle una importante fuente de ingresos al Estado, también afectó a los caficultores y a los productores de algodón, quienes fueron, al final, los que pagaron el precio más alto por esta medida.

Todos estos cambios, a la vez, produjeron una fragmentación y una reconstitución de la élite económica. El sector que fue más dependiente de la tenencia de tierra para extraer sus riquezas, fue golpeado fuertemente por las reformas que se implementaron en la década de 1980. Un segundo grupo, integrado por financieros, exportadores e industriales, que tuvieron una mayor capacidad para navegar en medio de la crisis, comenzaron a diversificar sus inversiones durante este período con la ayuda de la Agencia de Estados Unidos para el Desarrollo Internacional (USAID). El desarrollo del sector de servicios (incluyendo aquellos de naturaleza financiera), de la industria maquilera y de las exportaciones agrícolas no tradicionales fueron los puntos fuertes de su estrategia de producción diversificada. La modernización de la estructura económica salvadoreña mediante la creación de exportaciones no tradicionales fue un objetivo fundamental del gobierno estadounidense, que encontró un interlocutor válido en este sector modernizador del empresariado salvadoreño. Los Estados Unidos también contribuyeron a la modernización política de este sector de la élite económica mediante servicios de promoción y consultoría, así como por medio de la creación de instituciones de elaboración de análisis intelectual como la Fundación Salvadoreña para el Desarrollo Económico y Social (FUSADES) (Robinson 2003).

Cuando esta élite se vio enfrentada a la posibilidad de un cambio revolucionario en el sistema político y económico causado por la victoria del FMLN, se vio forzada a crear su propio partido político, ARENA, en septiembre de 1981. Los fundadores del partido provenían, en su mayoría, de los sectores oligárquicos (terratenientes, industriales y financieros), la Fuerza Armada y los grupos paramilitares. En sus primeros años, la organización se caracterizó por un estilo beligerante, por el uso de una retórica encendida y por recurrir a tácticas y formas de lucha violentas. Sin embargo, las transformaciones de la estructura económica del país, el apoyo norteamericano a la renovación política de la derecha y el 
exilio de algunos de los principales representantes de la vieja oligarquía terrateniente ayudaron a aumentar la influencia política del sector modernizante de la élite económica, que también se vio reflejado en la composición interna de ARENA. El sector terrateniente, radicalmente anticomunista, que dominó al partido en sus primeros años se vio sustituido, a raíz de su derrota electoral en los comicios legislativos de 1985, por un grupo que provenía de la burguesía modernizante. La nominación de Alfredo Cristiani, en 1988, como candidato presidencial para las elecciones de 1989 representaba a una coalición dominante que mandaba en ARENA a partir de ese momento. Las victorias electorales consecutivas de 1988 y 1989 fortalecieron las posiciones de este grupo y a su prestigio en el seno del partido.

Este sector de la élite, que a partir de ahora encabezaba al partido, tenía un gran interés en ponerle fin a la guerra en vez de perpetuarla. ${ }^{30}$ La magnitud del conflicto les hizo imposible comprometerse por entero en sus actividades financieras y comerciales mientras, por el otro lado, las demandas reivindicadas por el FMLN sobre la tierra con el objetivo de finalizar el conflicto ya no presentaban un peligro para su supervivencia. El hecho de que la tenencia de la tierra y la agroexportación tradicional hubieran perdido su importancia económica, así como el hecho de que el núcleo de la creación de la riqueza se desplazara hacia los sectores de comercio y servicio, hacían innecesario mantener la estructura coercitiva que otrora había garantizado el control sobre la fuerza de trabajo desde la década de 1930. Además, en el escenario de la nueva poliarquía que ahora se encontraba establecida en el país, la moderna élite empresarial ya no sentía la necesidad de confiar en la Fuerza Armada para representar y defender sus intereses, sino que ahora tenía sus propios instrumentos tales como ARENA y FUSADES, y estaban mejor adoptados al nuevo entorno político y económico nacional e internacional (Cardenal 2002: 111). Comparado con sus antecesores, Alfredo Cristiani y las fuerzas a las que representaba se encontraban mejor situados estructural y políticamente para entrar en negociaciones de paz con el FMLN. Por ello, cuando las circunstancias fueron propicias a partir de la ofensiva de 1989, este grupo estaba dispuesto a hacer una serie de concesiones políticas que estaban bajo su control y no contradecían sus intereses económicos fundamentales, los cuales, a fin de cuentas, facilitaban llegar a un acuerdo con el Frente.

\subsubsection{Cambios en la política estadounidense hacia El Salvador}

Hasta la década de 1970, la participación del gobierno estadounidense en El Salvador no era 
tan significativa si se le compara con su ingerencia en otros países de la región. No obstante, aumentó en la medida en que la crisis política empeoró y se hizo más evidente después del triunfo sandinista en julio de 1979.

Cuando Jimmy Carter asumió la presidencia, su administración (1977-1981) dio un giro en la política exterior norteamericana al hacer de la defensa y la protección de los derechos humanos una de las premisas de la relación de los Estados Unidos con los países en desarrollo. El Departamento de Estado norteamericano tenía instrucciones de proporcionar reportes anuales sobre los progresos alcanzados en materia de derechos humanos por parte de los países que recibían ayuda norteamericana, la cual estaba supeditada a que demostraran una mejora significativa en esta materia o, por lo menos, que probaran que estaban haciendo esfuerzos serios en este sentido. Con lo cual, los Estados Unidos tenían la intención de presionar a sus aliados autoritarios para que se democratizaran. Sin embargo, pronto se hizo evidente en el caso salvadoreño, que el supuesto compromiso moral que estaba guiando a la nueva política exterior era, en realidad, un arma diplomática que fácilmente cedió su lugar a los intereses estratégicos. En 1978, el gobierno estadounidense despachó un paquete de ayuda financiera de diez millones de dólares al gobier- no del general Carlos Humberto Romero, pese a que existía una abundante evidencia inculpadora de los asesinatos y desapariciones perpetrados por las fuerzas de seguridad y los escuadrones de la muerte desde la llegada de Romero al poder. Enfrentado al estallido del movimiento revolucionario en $\mathrm{El}$ Salvador y a raíz de la victoria del Frente Sandinista en julio de 1979, Carter escogió priorizar los intereses de seguridad de los Estados Unidos. A la luz de la posibilidad de que una victoria revolucionaria tuviera lugar en El Salvador, la administración norteamericana apoyó al sector moderado de la Fuerza Armada, en un intento de poner en un segundo plano a los grupos más conservadores en el control del Estado. La meta de la política exterior en ese momento era la de aislar tanto a la izquierda marxista-leninista como a la extrema derecha, y colocar las bases para la construcción de una democracia representativa alineada con Washington. La Junta Revolucionaria de Gobierno que tomó el poder a raíz del golpe del 15 de octubre de 1979 era, a los ojos de los Estados Unidos, el instrumento que les permitiría alcanzar ambas metas (Leogrande 1998: 41).

Cuando la primera Junta renunció en enero de 1980, la administración norteamericana se dedicó a la tarea de buscar una figura política con credenciales democráticas que pudiera ser aceptable para los militares salvadoreños. Esa figura 
era Napoleón Duarte, el dirigente del sector conservador del PDC, al que, a partir de ese momento, el Departamento de Estado promovería como imagen de moderación. La nueva Junta de Gobierno, controlada por los militares y ahora apoyada exclusivamente por el PDC, se convertiría, por ende, en la plataforma ideal desde la cual se lanzarían una serie de reformas estructurales dirigidas a debilitar y minar la base económica del poder de la oligarquía terrateniente. La reputación de Duarte como líder democrático que se había opuesto durante años a la dictadura militar le dio al gobierno norteamericano la posibilidad de ofrecerle a El Salvador suficiente apoyo militar para derrotar a los revolucionarios.

Frente al acercamiento progresivo de la izquierda armada y la izquierda moderada representada por el FDR, Carter optó por apoyar sin reservas a los militares y al PDC. Ni el asesinato del Arzobispo Romero en marzo de 1980, ni el de tres monjas estadounidenses, o incluso el de la propia dirigencia del FDR en el mes de noviembre de ese año, orquestado por sectores de la Fuerza Armada, fueron suficientes para cancelar la ayuda militar estadounidense al gobierno salvadoreño, el cual recibió casi seis millones de dólares de parte de los Estados Unidos, a principios de 1981.

Cuando el presidente Ronald Reagan asumió la presidencia
(1981-1989), la política exterior norteamericana en El Salvador se militarizó. Esto fue el resultado de una lectura sumamente ideologizada del conflicto interno salvadoreño. Para la nueva administración estadounidense, El Salvador era un campo de juego del enfrentamiento Este-Oeste, y era visto como el lugar donde, para citar al Secretario de Estado Alexander Haig, "debía trazarse la línea" (Leogrande 1998: 80). En otras palabras, era el lugar donde se frenaría el expansionismo cubano-soviético, después de la derrota de los intereses occcidentales en Vietnam, Irán o Nicaragua. La administración Reagan contempló la creación de un régimen marxista en la región como un riesgo intolerable que podría volverse una amenaza para sus rutas marítimas de abastecimiento, o albergar a fuerzas militares hostiles. Por todo esto, La inestabilidad política de El Salvador -y la de toda América Central, para el caso- era, desde la perspectiva de Reagan, un tema de seguridad nacional.

Debe decirse que la agresiva política exterior de Reagan encontró un cierto contrapeso en la Cámara de Representantes, que estuvo controlada durante ese período por el Partido Demócrata (Walter 2008_201). Los demócratas criticaban la aspiración de Reagan y su equipo de intensificar el conflicto salvadoreño, el cual rechazaban considerar como un producto del enfrentamiento Este-Oeste. ${ }^{31}$ Como 
señala de nuevo Knut Walter, para contrarrestar la oposición de la Cámara y para enfrentar las críticas emitidas de parte de un importante sector de la opinión pública con respecto a la intervención norteamericana en Centroamérica, la administración Reagan exageró sistemáticamente el peligro que suponía Centroamérica para la seguridad nacional norteamericana.

Con esto en mente, la política de Reagan resultó en un aumento exponencial de la ayuda militar a El Salvador durante la década de 1980. La ayuda no se limitaba a proveer financiamiento y armas, sino que se ampliaba a la participación de la $\mathrm{CIA}$ en operaciones encubiertas en El Salvador, al despliegue de asesores militares y al entrenamiento y organización de los denominados Batallones de Reacción Inmediata (BIRI). Según Walter (2008: 202), la ayuda militar a El Salvador superó los 950 millones de dólares entre 1980 a 1989 . El resultado palpable de este apoyo fue que la Fuerza Armada salvadoreña pudo tomar la iniciativa militar a partir de 1984 — hasta la ofensiva del Frente en 1989-, forzando así al FMLN a desistir de concentrar tropas y a utilizar una estrategia de "golpear y huir", lo cual disminuyó sus posibilidades de implementar ofensivas de gran escala que hubieran podido amenazar la estabilidad del gobierno. A largo plazo, esto resultó en un punto muerto militar, que tuvo un alto costo político para el FMLN, por cuanto se había vuelto evidente, a lo largo del tiempo, que los insurgentes eran incapaces de alcanzar el poder, mientras que los crecientes costos de la guerra contribuyeron a menguar el apoyo popular a las organizaciones guerrilleras.

Desde junio de 1981, como resultado del ascenso de Thomas O. Ender a Secretario Asistente de Estado para Asuntos Interamericanos, se sumó una nueva línea estratégica al enfoque inicial de la administración Reagan, la cual se había fundamentado casi exclusivamente en la provisión masiva de ayuda militar para derrotar a la insurgencia: la promoción de la democracia. Enders vio en la celebración de elecciones y en la liberalización del régimen político salvadoreño una estrategia para marginar políticamente al FMLN y para recabar el respaldo necesario para el apoyo militar norteamericano, tanto en Estados Unidos como en el exterior. La creación de una democracia representativa, por tanto, tuvo una función instrumental que estaba subordinada al objetivo principal: la derrota de la insurgencia a través de la ayuda militar. En la estrategia de Enders, si la izquierda no accedía a formar parte del sistema político, se comprobaría su negativa a renunciar a la violencia, por cuanto las elecciones eran la única salida política a la guerra. Al hacer esto, negaban la posibilidad de comenzar negociaciones con 
la insurgencia, en las cuales esta última podría lograr lo que había sido incapaz de lograr en el campo de batalla (Leogrande 1998: 127). Pese a su función instrumental, la celebración de elecciones regulares abrió el espacio político, lo cual, a su vez, permitió a los aliados civiles del FMLN insertarse en el sistema político en 1988. Esto contribuyó a que el FMLN experimentara un cambio de perspectiva con respecto a las posibilidades de la democracia representativa.

Paralelo a ello había otro objetivo crucial de la ayuda económica norteamericana: apoyar a una economía que se había visto seriamente debilitada por la guerra. Walter (2008: 203) calcula esta ayuda en unos 2,685 millones de dólares de 1979 a 1989, lo que permitió estabilizar la economía salvadoreña, la cual, de otra manera, hubiera colapsado en medio del conflicto. La intervención del gobierno estadounidense $y$, en particular, su capacidad de influir en la estrategia de la Fuerza Armada salvadoreña, de diseñar el nuevo sistema político y de financiar tanto el esfuerzo de guerra como sostener la economía del país, convirtieron al gobierno estadounidense un actor interno de la política salvadoreña durante el conflicto.

Desde 1987, la política de Reagan hacia Centroamérica se vio debilitada por el escándalo IránContras; por el Acuerdo de Esqui- pulas II, de agosto de 1987, el cual condenaba de manera indirecta el apoyo de Estados Unidos a los contras nicaragüenses; y por el Partido Demócrata, cuando éste tomó el control del Senado norteamericano. Más adelante, la distensión entre los Estados Unidos y la Unión Soviética (URSS) y la llegada de George $\mathrm{H}$. W. Bush a la Casa Blanca en enero de 1989, derivaron en que Centroamérica tuviera un peso considerablemente menor en la agenda de seguridad estadounidense. Contrario a la administración de Reagan, la de Bush tenía una visión bastante menos ideologizada del conflicto y estaba decidida a disminuir su onerosa ingerencia en la región. La posición soviética, que desde mediados de la década de 1980 había favorecido una solución negociada a los conflictos centroamericanos y la victoria de Violeta Chamorro en Nicaragua, en febrero de 1990, también formaron parte de esto.

Por ello, después del asesinato de los sacerdotes jesuitas salvadoreños en noviembre de 1989 y la subsiguiente presión del Congreso norteamericano para cortar a la mitad la ayuda militar proporcionada al ejército salvadoreño, condicionándola a que hubiera progresos en la investigación de los asesinatos, el Ejecutivo norteamericano estaba en condiciones de cambiar su punto de vista sobre el conflicto sin mayores costos políticos. A partir de 1990, el gobierno estadounidense ejerció presión y favoreció las negociacio- 
nes entre el gobierno salvadoreño y el FMLN.

\subsubsection{Cambios en la posición de los aliados del FMLN}

El gobierno cubano permaneció fiel a la posición de promover el internacionalismo revolucionario, lo cual equivalía al apoyo sostenido al FMLN durante la guerra. Los contactos de las organizaciones político-militares con Cuba se remontan a principios de la década de 1970, aunque mantuvieron un perfil bajo hasta 1979. ${ }^{32}$ Esto se debió principalmente al hecho de que las condiciones que acordaron La Habana y los partidos comunistas latinoamericanos en 1975 para que la primera apoyara a las organizaciones armadas del continente no habían sido satisfechas en El Salvador: altas probabilidades de triunfo, consentimiento soviético y unidad de las fuerzas revolucionarias (Castañeda 1995: 101). Estas condiciones se dieron en 1979.

El ejemplo de la unificación de las tres tendencias del sandinismo y la victoria de la revolución nicaragüense, combinada con la debilidad militar de las organizaciones político-militares salvadoreñas, motivaron que estas últimas se unieran. Junto a esto, la intervención personal de Fidel Castro hizo más fácil superar la desconfianza entre los diferentes grupos, allanando el camino para llegar a los acuerdos que dieron paso al surgimiento del FMLN. Asimismo, Castro también facilitó las negocia- ciones ulteriores entre las diferentes organizaciones en diciembre de 1979, en La Habana. Según algunas fuentes, el líder cubano desempeñó un papel importante en la creación del FMLN al condicionar su apoyo a la unidad entre las organizaciones salvadoreñas. A partir de entonces, Cuba se convertiría en plataforma logística, campo de entrenamiento, hospital y aliado fundamental de la insurgencia salvadoreña.

Pese a que este apoyo no desaparecería en ningún momento durante la guerra, bajó su perfil a partir de 1982 - 1983. La amenaza norteamericana de "ir a la fuente" de la insurgencia salvadoreña (Lafeber, 993: 278), la posición conservadora de los soviéticos y la imposibilidad de obtener una victoria rápida por parte del FMLN hizo que el gobierno cubano se volviera más cauteloso. Todo ello condujo a este último a recomendar a los dirigentes del FMLN promover una estrategia consistente en combinar la lucha armada y la negociación con el gobierno al menos desde finales de $1982^{33}$. Los cubanos intentaron persuadir a los revolucionarios salvadoreños de lo oportuno de buscar un entendimiento con su gobierno como una forma de aplacar a la administración Reagan, buscando con esto contribuir a garantizar la supervivencia de la revolución nicaragüense.

Con respecto a Nicaragua, algunos sectores de la dirigencia del Frente Sandinista de Liberación 
Nacional (FSLN) cooperaron con los revolucionarios salvadoreños durante la guerra. Al igual que Cuba, los sandinistas se enorgullecían de su internacionalismo revolucionario, pero también contribuían a pagarles la deuda de solidaridad que tenían con sus compañeros salvadoreños. ${ }^{34}$ Nicaragua sirvió como corredor y como depósito logístico de provisiones, proporcionó apoyo político constante - permitiendo, incluso, que el FMLN se instalara abiertamente en el país durante varios años-y le proporcionó armas durante el conflicto. Debe notarse que el endurecimiento de las posiciones norteamericanas obligó a los nicaragüenses a bajar el perfil de sus relaciones oficiales con el FMLN a partir de 1983. La prueba de lo anterior está en el hecho de que el apoyo que los salvadoreños recibían de los sandinistas a partir de ese momento provino fundamentalmente de la dirigencia del partido y del ejército, pero no del gobierno nicaragüense como tal. ${ }^{35}$ La derrota electoral del FSLN en febrero de 1990 resultó en que los revolucionarios salvadoreños tuvieran que enfrentar desafíos mayores que cuando recibía provisiones desde Nicaragua.

En el caso de la Unión Soviética, la llegada de Mijaíl Gorbachov (1985-1991) redefinió las prioridades de la política exterior soviética, por cuanto se buscó reasignar sus ya agotados recursos económicos y canalizarlos hacia la satisfacción de las necesidades internas. Desde 1988, se volvió claro que la administración Gorbachov había transformado su política hacia el tercer mundo, al reconocer que los Estados Unidos tenían intereses nacionales legítimos y que era necesario para ambas potencias respetar sus zonas de influencia ya establecidas. La Unión Soviética renunció a exportar la revolución y dejó de proporcionar soluciones militares a las diversas crisis regionales que estaban en marcha en aquel tiempo y, más aún, comenzaron a buscar una salida negociada a los conflictos armados dentro de una perspectiva de cooperación con los Estados Unidos. Estos cambios tuvieron un impacto importante en la crisis centroamericana. En el caso salvadoreño, los soviéticos insistieron reiteradas veces en 1990 en que el FMLN negociara con el gobierno salvadoreño en presencia de la ONU y sugirieron que si los Estados Unidos dejaban de apoyar al gobierno salvadoreño, el Frente debería abandonar las armas. En febrero de ese año, los soviéticos parecían haber llegado a un acuerdo con Estados Unidos para encontrarle una solución negociada al conflicto salvadoreño.

\subsection{Factores internos}

\subsubsection{Cambios en el equilibrio de poder dentro del FMLN}

La derrota de la ofensiva de 1981 mostró que dentro del FMLN 
existían, al menos, dos concepciones bien diferenciadas sobre la estrategia y los fines de la revolución. La primera estaba representada por el líder de las FPL, Salvador Cayetano Carpio. Para él, la revolución debía conducirla una alianza obrero-campesina, y la victoria se alcanzaría a través de la lucha armada y por medio del uso de una estrategia de guerra popular prolongada. En la práctica, esto se tradujo en que Carpio rechazara formar alianzas con otras fuerzas sociales y que considerara la negociación estratégica con el gobierno con muchas reservas, ya que, desde su punto de vista, la negociación debería usarse solamente para propósitos tácticos. Junto a esto, Carpio veía en las FPL la verdadera expresión de la vanguardia revolucionaria y tenía una desconfianza sumamente arraigada hacia las otras organizaciones armadas y hacia el PCS. Estos recelos se vieron alimentados por algunos movimientos de aproximación hacia la Internacional Socialdemócrata realizados por la RN y el ERP a lo largo de 1982, y por la insistencia de Carpio de que el FMLN se declarara marxista - leninista, lo cual rechazaban las otras dos organizaciones. Con estos elementos, Carpio tenía la impresión en aquellos momentos de que RN y ERP estaban planeando abandonar el FMLN y unirse a la socialdemocracia junto al MNR de Guillermo Ungo ${ }^{36}$.

Por el contrario, la postura mayoritaria dentro del FMLN, defendida entre otros por el Secretario
General del PCS, Schafik Handal, se basaba en desarrollar una relación más cercana con los sectores más moderados de la Democracia Cristiana y en iniciar un proceso de negociación para finalizar la guerra. El punto de vista de Carpio fue rechazado por la mayoría de los comandantes del FMLN en el verano de 1982, quienes accedieron, en su lugar, a promover una estrategia dual de lucha armada y negociaciones con el gobierno - una estrategia a la cual se oponía Carpio, pero que se vio forzado a aceptar, probablemente por la presión que ejercieron Fidel Castro y las otras organizaciones. El propósito de esta estrategia dual para el FMLN era ocupar posiciones en un futuro gobierno de coalición junto a al Democracia Cristiana y, a partir de ahí, con el apoyo popular que pensaban que obtendría el Frente, realizar su proyecto político. La posibilidad de tomar el poder y de tener un control exclusivo sobre el aparato de Estado por medio de la lucha armada no estaba descartada, pero se abrió una segunda ruta que podría ponerle fin al conflicto en un escenario de poder compartido.

Todo lo anterior provocó una crisis en la comandancia del Frente, que se reflejó en el hecho de que Carpio, se negara a asistir a las reuniones posteriores de la misma, a las que en cambio asistió Mélida Anaya Montes (Ana María), quien mostraba una mayor sensibilidad por la unidad del FMLN ${ }^{37}$. 
La postura de Carpio también fue objeto de rechazo por parte de la mayoría de los comandantes de su propia organización en una reunión del Comando Central de las FPL sostenida en Managua a finales de 1982 o inicios de 1983, donde prevaleció la posición que favorecía una estrategia que combinaba la lucha armada y la negociación. Junto a ello, al menos parte de la comisión política de las FPL estaba propugnando en aquel momento una renovación del liderazgo de la organización, lo que situó a las FPL en una situación delicada a inicios de 1983. Este conflicto fue muy probablemente el detonante del asesinato de Anaya Montes en Managua, el 6 de abril de 1983, y del suicidio de Carpio unos días después, el 12 de abril. ${ }^{38}$

La muerte de su Secretario General permitió la apertura política de las FPL, la cual estaba ahora en manos de una generación de militantes más jóvenes y más pragmáticos. En opinión de Facundo Guardado: "todo el debate que se creó alrededor del asesinato de Anaya contribuyó, en gran medida, a desfanatizar a las FPL". ${ }^{39}$ La nueva dirigencia, integrada por Salvador Sánchez Cerén como Secretario General y por Dimas Rodríguez y Salvador Guerra como los números dos y tres de la organización, respectivamente, tuvo una mayor capacidad de articulación y acercamiento hacia el resto del movimiento revolucionario, así como una mejor disposición para alcanzar compromisos políticos. Hay que resaltar que la crisis de las FPL se saldó con la escisión de parte de la estructura urbana de las FPL en San Salvador (el denominado posteriormente Frente Clara Elisabeth Ramírez) y de algunos integrantes del aparato internacional y de finanzas, quienes no estuvieron de acuerdo con la versión ofrecida de los acontecimientos ni con el giro estratégico de la organización.

\subsubsection{El giro estratégico}

La desaparición de Carpio, dirigente de la organización más poderosa del FMLN, hizo más fácil adoptar la estrategia dual de lucha armada y negociación que impulsó el FMLN hasta 1989. Uno de los primeros resultados que arrojó este giro estratégico fue la publicación de la propuesta del Gobierno de Amplia Participación (GAP), el 31 de enero de 1984, dos meses antes de las elecciones presidenciales. El GAP, que se convirtió en la plataforma política oficial del FMLN, propuso la creación de un Ejecutivo plural de "salvación nacional", que incluiría a "la burguesía no oligárquica" y debería convocar a elecciones en el menor lapso posible. A fin de integrar este gobierno, el Frente proponía iniciar un proceso de diálogo y negociación, y ofreció un cese del fuego una vez que el proceso estuviera encaminado. Pese a sus motivaciones tácticas, este documento demostró un importante cambio 
político por parte de las organizaciones guerrilleras. La propuesta del GAP significaba que la alianza del FMLN-FDR estaba optando, a partir de ese momento, por una solución negociada si se cumplían determinadas condiciones, incluyendo las garantías para la integridad física de sus militantes y el reconocimiento oficial de su representatividad como fuerza política.

Este cambio de perspectiva, y la llegada al poder del PDC, crearon las condiciones necesarias para las primeras conversaciones públicas entre el gobierno y los grupos guerrilleros, en La Palma, en octubre de 1984 y en Ayagualo, en noviembre de ese mismo año. Estas pláticas concluyeron debido a la presión ejercida por parte de la Fuerza Armada, que no veía en la solución negociada al conflicto una opción aceptable. En mayo y octubre de 1987 habría un contacto mayor con un gobierno que estaba sumamente debilitado por la guerra y la prolongada crisis económica, y por su incapacidad de imponerse sobre la Fuerza Armada, apoyada por los Estados Unidos en su decisión de derrotar a los insurgentes. El FMLN, por su parte, estaba persuadido de que las masas se estaban radicalizando y que una derrota del gobierno sería posible en el futuro cercano. Con estas perspectivas, las pláticas fueron tácticas por naturaleza para ambas partes, y no rindieron resultados sustanciales. Esto también pasó en las pláticas entre los representantes del FMLN y del gobierno de ARENA, sostenidas en México y San José en septiembre y noviembre de 1989. Para el Frente, estas pláticas eran parte de una contraofensiva estratégica, en la cual, la demostración de fuerza militar sería necesaria para obligar al gobierno a negociar (Dunkerley 1994: 68).

Los resultados de la ofensiva de noviembre de 1989 apoyaron la postura de aquellos que, dentro del FMLN, respaldaban una solución negociada al conflicto. El hecho de que no hubo ninguna insurrección popular, como esperaban algunos comandantes, demostró que el pueblo salvadoreño estaba cansado de la guerra y, más que de insurrección, lo que ansiaban era el fin de la guerra de cualquier manera. La población estaba agotada después de muchos años de conflicto, evidenciado por la creciente dificultad para los grupos guerrilleros para reclutar combatientes. ${ }^{40}$ Mientras tanto, la solidaridad internacional estaba disminuyendo y los cambios en el bloque oriental plantearon un mayor grado de incertidumbre en el futuro de las luchas de liberación nacional alrededor del mundo. Todo esto contribuyó a que prevaleciera el pragmatismo dentro del FMLN, después de la ofensiva de 1989.

\subsubsection{Cambio de fines y de medios}

La extensión del conflicto y la incapacidad de obtener una victoria 
militar definitiva desataron un cambio político y estratégico gradual en el FMLN. Hacia 1983, el Frente se desplazó de su posición política inicial, en la cual la revolución y el socialismo se veían como la única solución a los problemas del país, y la lucha armada era vista como la única forma de alcanzarlos, a un reconocimiento paulatino de la negociación política como opción alternativa. Una tercera perspectiva surgió en 1989, en la que la celebración de elecciones transparentes, el funcionamiento independiente del poder judicial y la desmilitarización se volvieron los principales objetivos de la lucha —una lucha en la que se combinaban las negociaciones con la presión militar. En otras palabras, implementar reformas dentro del marco de una democracia representativa y la economía de mercado, se identificaba ahora con una revolución a la cual se tildaba como democrática. A partir de ahí, la estrategia del Frente descansaría en la participación en elecciones como medio para la toma del poder $y$, a partir de ahí, comenzar la transición hacia una nueva sociedad. El proyecto de "revolución democrática" se presentó en varios documentos publicados entre 1989 y 1990. En enero de 1989, el Frente hizo pública su Propuesta para convertir las elecciones en una contribución a la paz, en la cual accedía a participar en las elecciones presidenciales que se celebrarían en marzo si se suspendían durante seis meses y durante el tiempo que tomaría para que se satisficieran algunos prerrequisitos mínimos para asegurar su transparencia. Simultáneamente, Joaquín Villalobos, el dirigente del ERP, publicó un documento titulado Perspectivas de victoria y modelo revolucionario. Este documento planteaba la necesidad de llevar a cabo una revolución adaptada a la realidad salvadoreña, en la cual trabajadores y campesinos, pero también la clase media, se convertirían en motores de ese proceso. Desafiaba la posibilidad de adoptar un sistema de partido único y aceptaba las elecciones como un medio válido para obtener el poder político, en la medida en que se celebraran en un clima de oportunidades iguales para todos los contendientes. Además, aceptaba la existencia de la propiedad privada, el pluralismo político, la libertad de prensa y el papel de la iglesia católica. Una vez que las negociaciones estaban en curso, el FMLN publicó su Proclama a la nación. La revolución democrática, en septiembre de 1990, en la que se esbozaba el programa que pretendía alcanzar a través de las conversaciones de paz y la posición de apertura política antes mencionada.

A partir de 1990, el uso de la violencia vino a ocupar un papel subordinado al progreso de las negociaciones. La desmilitarización del Estado se volvió el tema central de las negociaciones, por encima de la transformación socioeconómica. El Frente asumió que 
esta última tendría lugar una vez que los revolucionarios hubieran alcanzado el poder por medio de las elecciones, aunque los comandantes de la guerrilla buscaron, durante las negociaciones, que se les garantizara la propiedad de tierras a los trabajadores agrícolas que fueron miembros de su ejército o sus bases de apoyo.

El desarme del FMLN se discutió en septiembre de 1991, cuando se habían alcanzado algunos de los acuerdos más importantes en las negociaciones, por cuanto los grupos guerrilleros no estaban dispuestos a desmantelar sus estructuras armadas sin haber logrado compromisos firmes. En ese mes, el FMLN dispuso un cese al fuego unilateral, en un punto avanzado de las negociaciones que le dio tiempo a los comandantes guerrilleros para discutir con los combatientes las decisiones que se estaban haciendo, y para lograr el apoyo de la militancia para deponer sus armas (Buchanan y Chávez 2008_21).

\section{La transición a la política democrática}

Los acuerdos de Chapultepec posibilitaron a la izquierda acceder al sistema político, que se desmantelara el sistema represivo y que cambiaran las relaciones entre civiles y militares, lo cual sentó las bases para la desmilitarización de la sociedad. A cambio, el FMLN tuvo que renunciar a modificar el orden económico, pese a haber denunciado al sistema económico como una de las causas de la guerra. Puede decirse que el corazón del acuerdo entre la insurgencia y el gobierno fue la desmilitarización y la democratización del régimen, a cambio de aceptar la economía de mercado.

\subsection{La implementación de los acuerdos de paz}

Como resultado de las negociaciones, la Fuerza Armada sufrió un proceso de reformas. La primera de ellas fue que su misión se redujera a defender la soberanía nacional y la integridad territorial, privándola de la función establecida en el artículo 221 de la Constitución de 1983, la cual le otorgaba el papel de mantener el orden interno. A partir de esta reforma constitucional acordada como parte de los acuerdos de paz, los militares solo podían mantener el orden interno como algo excepcional y con el previo consentimiento del presidente. Además, la Fuerza Armada fue reducida y depurada, aunque en una extensión limitada (ver el apartado 3.3), y se estableció la base para cambiar su sistema educativo. Con respecto al desmantelamiento del sistema represivo, se disolvieron la Guardia Nacional y la Policía de Hacienda y se fijó un calendario para disolver la Policía Nacional. Estas fuerzas fueron sustituidas por la PNC, que estaba compuesta por ex guerrilleros 
y antiguos miembros de la Policía Nacional, así como de personal que se había unido recientemente a sus filas. ${ }^{41}$ Además, la Agencia Nacional de Inteligencia se disolvió y se creó un nuevo Organismo de Inteligencia del Estado, dirigido por civiles.

La Comisión de la Verdad se creó para supervisar la investigación y resolución de denuncias de violaciones a los derechos humanos. Sin embargo, pese a sus recomendaciones, la Asamblea Legislativa, controlada por ARENA, aprobó una ley general de amnistía para todos aquellos implicados en crímenes políticos, lo cual, en la práctica, evitaba que se sancionara a cualquier individuo al que se le hallara culpable de violaciones.

Con respecto a los temas económicos y sociales, los acuerdos regularon la tenencia de la tierra en las zonas conflictivas y previeron algunas medidas para aliviar el costo social de los ajustes estructurales, promoviendo la creación de un Foro Consultivo. Esta última medida, que pretendía buscar consensos en el diseño de la política económica y las leyes laborales, apenas funcionó, por cuanto no era vinculante. Por último, pero no por ello lo menos importante, los acuerdos hicieron posible reformar el sistema de justicia y crear la figura del Procurador para la Defensa de los Derechos Humanos. El código electoral también sufrió reformas.

\subsection{La evolución política del FMLN}

Como consecuencia de los acuerdos de paz, el FMLN se desmovilizó el 15 de diciembre de 1992, y se inscribió como partido político. Esto marcó el inicio de una nueva etapa para la organización - a partir de ahora era un partido político legítimo. Como organización partidaria, el Frente experimentó un crecimiento lento, pero sostenido, hasta que se volvió la primera fuerza política en el país y ganó la presidencia en 2009.

Este itinerario no estuvo exento de dificultades. El fin de la guerra, la crisis de la ideología socialista y las luchas internas por el poder, socavaron la cohesión de las otrora organizaciones revolucionarias. Desde la firma de los acuerdos, se hizo evidente que había dentro del Frente diferencias ideológicas y luchas por el poder. En 1994 y 1995, las diferencias más obvias eran entre la RN y el ERP y el resto del Frente. Estas dos organizaciones propusieron abandonar el marxismo-leninismo y convertir al FMLN en un partido socialdemócrata. Ambas organizaciones también objetaron el proceso de toma de decisiones dentro del Frente, el cual los afectaba sistemáticamente, puesto que sus posturas se encontraban siempre en minoría, comparadas con las de los otros grupos. El conflicto concluyó cuando la RN y el 
ERP dejaron del FMLN en 1994 y crearon un nuevo (y fallido) partido político. Estaba claro que el FMLN era incapaz de manejar sus conflictos internos de forma constructiva. En 1995, las tres organizaciones restantes (PCS, FPL y PRTC) optaron por disolverse y después refundar el FMLN como organización unificada. A partir de ese momento, se pudo observar la creación de facciones internas dentro del Frente. Estas facciones representaban diferentes perspectivas sobre lo que deberían ser la definición ideológica y la estrategia política del partido. El resultado de estas diferencias fue la expulsión de los dirigentes de las facciones minoritarias o de aquellas que tenían menos peso en la estructura de la organización. Por ello, Facundo Guardado, ex comandante de las FPL, fue expulsado en octubre de 2001, y Francisco Jovel, otrora Secretario General del PRTC, también fue expulsado en 2002.

Una constante que ha sido patente a lo largo de estos años ha sido que, mientras para algunos comandantes los acuerdos de paz significaron la culminación de las grandes transformaciones que necesitaba el país, para otros, eran el punto de partida desde el cual se realizarían cambios más profundos en la estructura económica y social de El Salvador.

A partir del fin de la guerra y hasta 2004, el Frente se encontró en un período en el que su ideología y su proyecto político se encontraron en disputa. Algunos sectores, que apoyaban mantener al FMLN como una organización marxistaleninista sumamente ideológica (el ala socialista revolucionaria) chocaron con aquellos que favorecían un giro hacia la conversión a un partido de centro-izquierda (el ala renovadora). Desde 2004, a raíz de la toma de control del aparato partidario por parte del ala socialista revolucionaria bajo el liderazgo de Schafik Handal, el partido adoptó una estrategia de transición al socialismo, que pasaría por la toma del poder del Estado y la profundización de la democracia. Se planteó la posibilidad de crear una serie de alianzas políticas amplias con sectores no revolucionarios como medio para llegar al poder. Esta fue una política de colaboración táctica con las fuerzas políticas a las que la dirigencia del FMLN consideraba como democráticas, pero no de izquierda. ${ }^{42}$

En esencia, esta estrategia es muy similar a la que postuló el PCS en la década de 1970: tomar el poder mediante elecciones en una alianza con otras fuerzas políticas y, a partir de ahí, comenzar a transformar el sistema político y económico. Existen diferencias cualitativas obvias con respecto al significado del concepto de socialismo que sostenía el Frente en la década de los ochenta. Este proyecto socialista ya no rechaza la existencia de la propiedad privada, aunque reduce su 
papel en la economía y la subordina al interés social. No se opone a la democracia representativa por principio, aunque se propone, al menos en el papel, Ilevarla a niveles más profundos y más radicales a través de lo que llama "control popular".

Pese a sus luchas internas, hacia 2000 el FMLN devino la fuerza principal dentro de la Asamblea Legislativa y durante muchos años controló la alcaldía de San Salvador. Fue, de hecho, la mayor cohesión ideológica y la coherencia programática del partido, así como la autonomía de su dirigencia, lo que le permitió formar alianzas con sectores ajenos al FMLN, a partir de la designación del periodista Mauricio
Funes como candidato presidencial para las elecciones de 2009.43 La fórmula presidencial, con Salvador Sánchez Cerén como aspirante a la Vicepresidencia, se hizo pública en septiembre de 2007.

El FMLN derrotó a ARENA por primera vez en las elecciones presidenciales por una diferencia de casi 70,000 votos y obtuvo mayoría absoluta en la primera ronda (51$3 \%$ contra el $48.7 \%$ de ARENA) El Frente también venció al partido de derecha en las elecciones legislativas (35 escaños para el FMLN contra 32 de ARENA). Casi treinta años después de su fundación, el FMLN gobierna actualmente los destinos de El Salvador.

\section{Conclusión}

El movimiento revolucionario salvadoreño surgió como respuesta al régimen político autoritario que mantuvo a la mayoría de la población en una situación de exclusión política y económica. Contra el cierre de espacios de participación política y la represión de las exigencias del movimiento popular de democratización y mejoras económicas, algunos sectores disidentes del Partido Comunista y la juventud católica radical optaron por la lucha armada como medio para alcanzar una transformación política y económica profunda de El Salvador. Las fuertes raíces de las organizaciones guerrilleras en el movimiento popular, les permitie- ron desarrollarse como un amplio movimiento revolucionario que enfrentó al Estado en una guerra civil durante casi doce años.

Para enfrentar el desafío planteado por el FMLN, el Estado salvadoreño, con el apoyo de los Estados Unidos, lanzó una estrategia de reforma política y un aumento de la actividad militar. La liberalización del régimen político, la reforma agraria y la modernización y el aumento del número de efectivos de la Fuerza Armada fueron los elementos principales de la estrategia gubernamental. Por último, esta estrategia evitó el triunfo militar de un ejército revolucionario cuyo apoyo 
externo era mucho menor al de su oponente y que no pudo convencer a amplios sectores de la población de la legitimidad de su proyecto político.

La incapacidad para derrotar al gobierno provocó cambios en el equilibrio del poder dentro del FMLN y desató cambios graduales dentro de la estrategia y el proyecto político de los revolucionarios. Durante la década de 1980, el Frente se desplazó de una postura política en la que la revolución, la lucha armada y el socialismo eran consideradas como las únicas soluciones posibles para la crisis nacional, hacia una posición, al final de la década, donde la celebración de elecciones limpias, contar con un poder judicial independiente y desmilitarizar al Estado se convirtieron en los principales objetivos de la lucha —una lucha que combinaría la negociación con la presión militar. Esta sería la agenda y la estrategia que el FMLN mantuvo hacia las negociaciones de paz.

Todo esto muestra que, en el caso salvadoreño, adaptar los fines del movimiento se volvió un prerrequisito para la transición hacia una estrategia política. Pese a la imagen de rigidez ideológica que proyectaban algunas organizaciones revolucionarias, fueron considerablemente flexibles y respondieron continuamente adecuando su estrategia y su discurso a los cambiantes entornos políticos y militares. El papel de la dirigencia fue crucial con respecto a esta adaptación. Dadas las características organizativas de estas organizaciones (una jerarquía y unos niveles de autoridad y de responsabilidad claramente definidos), las principales decisiones estratégicas y la redefinición de los objetivos de la lucha se tomaron dentro de los pequeños grupos dirigentes y luego fueron aceptados por parte de la militancia.

Los acuerdos de paz de Chapultepec fueron un instrumento muy efectivo para insertar a la izquierda revolucionaria en el sistema político y para desmilitarizar al Estado. En este sentido, la transición hacia la democracia en El Salvador, que fue resultado de los acuerdos, fue el producto del desafío que planteó la insurgencia, aunque la democracia representativa no era parte de la agenda inicial, ni de los insurgentes, ni de la Fuerza Armada. Pese a que hubo algunos incidentes de violencia después de los acuerdos —de forma destacada, el asesinato de dos comandantes del PRTC-, puede decirse que las garantías de seguridad ofrecidas a los combatientes desmovilizados de la guerrilla operaron con efectividad. La presencia de los observadores de paz de la ONU, la presión de la comunidad internacional sobre el gobierno y los militares, el desmantelamiento de los cuerpos de seguridad y la construcción de una nueva fuerza de policial civil que integraba a ex combatientes del FMLN, son algu- 
nos elementos que explican estos resultados.

Empero, estos acuerdos dejaron muchos temas importantes sin resolver. La estructura económica permaneció intacta, lo cual explica por qué El Salvador sigue siendo uno de los países con el nivel más alto de desigualdad de ingresos. Por otro lado, la transición a la paz se vio acompañada de la implementación de políticas económicas neoliberales. La reducción del gasto público en el contexto de una economía sumamente dañada por la guerra, y el bloqueo de cualquier indicio de una política económica redistributiva, evitaron una mejora de la situación económica para la mayoría de los salvadoreños. Como resultado de lo anterior, durante las dos últimas décadas la economía salvadoreña ha sido incapaz de crear suficientes empleos para los miles de jóvenes que entran al mercado laboral. Esta es, al menos, una de las razones que explican los altos niveles de violencia social existentes hoy en día. Más aún, aunque la comunidad internacional hizo una inversión considerable en la implementación inmediata de los acuerdos, dicho apoyo se vio grandemente reducido una vez concluida la misión de la ONU. Un país con pocos recursos, desvastado por una guerra de doce años, hubiera necesitado un plan de reconstrucción económica financiado por la comunidad internacional, que hubiera ayudado a hacer viable la economía salvadoreña a largo plazo. Este punto ilustra la conducta del actor internacional más importante en la región: el gobierno de Estados Unidos, que pudo invertir un millón de dólares diarios durante casi una década para derrotar a la insurgencia, pero no hizo un esfuerzo similar para ayudar a El Salvador a reconstruir su economía después de la guerra.

Con respecto al FMLN, con la llegada de la paz se volvió claro que, en gran medida, el Frente había sido una alianza de conveniencia para luchar contra un enemigo común. Después de la guerra, afloraron las diferencias ideológicas, así como la lucha interna por el control del Frente en las nuevas circunstancias. La incapacidad de los dirigentes del Frente para resolver sus diferencias de forma constructiva y para ponerse de acuerdo en un modelo de partido que satisficiera a todas sus facciones internas, se hizo evidente durante la década de 1990. También se volvió claro que dichos conflictos fueron grandes luchas entre la élite del partido, porque los antiguos comandantes que se vieron expulsados del FMLN no fueron seguidos masivamente por la militancia.

Una vez resueltos los conflictos internos, a principios de la década de 2000, el FMLN podía ofrecer al electorado salvadoreño una imagen de cohesión interna y de coherencia ideológica, que contribuyó a pro- 
yectarlo como un partido apto para gobernar los destinos del país.

Finalmente, el movimiento revolucionario dejó detrás de sí otra herencia de largo aliento. La experiencia de la lucha armada y de participación política cambió las vidas de muchas mujeres involucradas y abrió paso, después de la guerra, a la creación de organizaciones de mujeres y feministas, como Las Dignas o Las Mélidas. Además, antiguos militantes revolucionarios construyeron decenas de ONG y de organizaciones sociales de todo tipo. El papel de estas organizaciones fue crucial, como proveedoras de diferentes servicios en un contexto de falta voluntad o incapacidad, por parte del Estado, de resolver los problemas económicos

NOTAS

1 Este trabajo se publicó originalmente en inglés bajo el título From Revolutionary War to Democratic Revolution. The Farabundo Martí National Liberation Front in El Salvador, Berghof Transition Series, volumen 8, Berghof Forschungzentrum für konstruktive Konfliktbearbeitung, Berlín, 2010. Agradecemos al autor por permitirnos verterlo al español.

2 Por ejemplo, Joaquín Villalobos Huezo, Ana Guadalupe Martínez y Rafael Arce Zablah, del ERP; Francisco Jovel y Nidia Díaz, del PRTC; Eduardo Sancho y Carlos Eduardo Rico Mira, de la RN; Felipe Peña Mendoza, Medardo González y Atilio Montalvo, de las FPL, entre muchos otros. y sociales de la población. Además de esto, durante la década pasada, algunas organizaciones populares fundadas por cuadros medios del FMLN protagonizaron algunas de las más importantes movilizaciones contemporáneas en El Salvador. Las luchas contra el tratado de libre comercio con Estados Unidos, contra las empresas mineras altamente contaminantes o, en general, a favor de una democratización más profunda de la sociedad salvadoreña, han sido conducidas en muchos casos por antiguos activistas del Frente. Puede decirse que la insurgencia legó una cultura de movilización y participación ciudadanas entre los sectores de la sociedad que habían sido excluidos de la vida política en el pasado.

3 La "Guerra del fútbol" fue un breve conflicto armado entre Honduras y El Salvador, que tuvo lugar en julio de 1969. La guerra estuvo motivada por las tensiones surgidas a raíz de la presencia de varios centenares de inmigrantes salvadoreños en Honduras. Los detonantes del conflicto fueron los enfrentamientos entre los fanáticos futboleros de ambos países, en el contexto de una ronda clasificatoria para el mundial de fútbol.

4 Algunos ejemplos de lo anterior son la represión de una protesta estudiantil acaecida el 30 de julio de 1975, que provocó las muertes de docenas de estudiantes; las masacres de campesinos en La Cayetana, Tres Calles y Chinamequita en 1974, o el acribillamiento de manifestantes en 


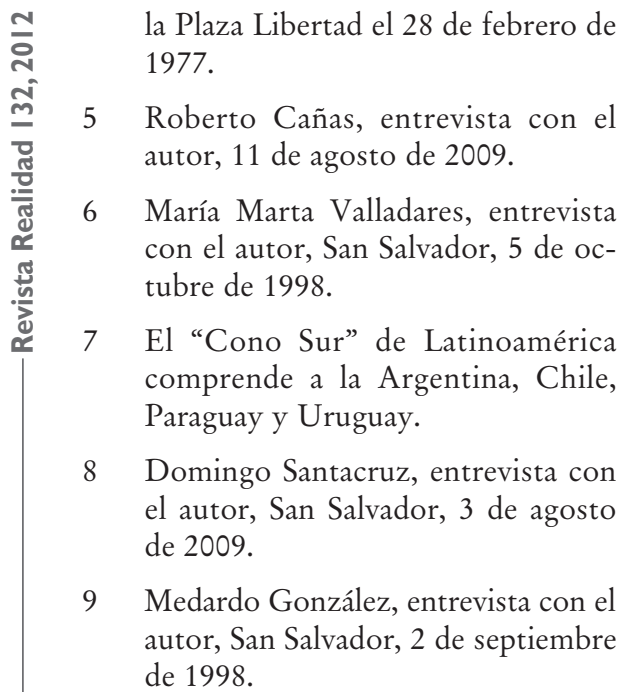

10 Atilio Montalvo, entrevista con el autor, San Salvador, 2 de septiembre de 1998.

11 El líder de más alto nivel del ERP desde 1977 hasta 1993.

12 Medrano fue más tarde comandante y miembro de la Comisión Política del ERP. Entrevista del autor con Juan Ramón Medrano, San Salvador, $1^{\circ}$ de octubre de 1998.

13 Algunos de ellos habían participado también en un efímero intento de organización armada denominado Acción Revolucionaria Salvadoreña (ARS) hacia 1966. Organización que llevó a cabo algunas acciones de sabotaje antes de ser desmantelada por la policía.

14 Sonia Aguiñada Carranza, entrevista con el autor, San Salvador, 11 de agosto de 2009 .

15 María Marta Valladares Mendoza, entrevista con al autor, San Salvador, 5 de octubre de 1998.
16 Roberto Cañas, entrevista con el autor, 11 de agosto de 2009.

17 Se trataba de los hermanos Inocencio e Higinio Alas. Sobre quien tuvo mayor responsabilidad en la creación del FAPU existen valoraciones encontradas. Valoraciones sobre las que no se discute aquí por falta de espacio.

18 El Partido Comunista — bajo la etiqueta electoral del UDN- se unió al socialdemócrata Movimiento $\mathrm{Na}$ cional Revolucionario (MNR) y el PDC bajo el membrete de la UNO.

19 Leo Cabral, entrevista con el autor, San Salvador, 30 de septiembre de 1998.

20 Especialmente, las FPL y el ERP, las dos organizaciones mayores, gracias a las cuales una fuerte base de apoyo campesino fue creciendo desde finales de 1970, principalmente en los departamentos de Cuscatlán, Cabañas, San Vicente, Morazán, San Miguel y Usulután.

21 Atilio Montalvo, entrevista con el autor, San Salvador, $1^{\circ}$ de octubre de 1998.

22 A la red de militantes prisioneros en las cárceles salvadoreñas también se le conocía como "el quinto frente".

23 Las fuerzas del PCS y del PRTC eran sumamente escasas durante la guerra.

24 El Frente Sandinista de Liberación Nacional (FSLN) encabezó el gobierno nicaragüense desde 1979 a 1990.

25 Esta estrategia la desarrolló principal pero no exclusivamente el ERP. 
26 Desde noviembre de 1990 hubo una escalada militar después del lanzamiento de una fuerte ofensiva por parte del FMLN.

27 COPAZ estaba integrada por representantes del gobierno, el FMLN, la Iglesia Católica, Naciones Unidas y los principales partidos políticos.

28 Se organizaron elecciones para integrar la Asamblea Nacional Constituyente en 1982 y, además, elecciones presidenciales de 1984 y 1989, que fueron ganadas por el PDC y ARENA, respectivamente, así como elecciones legislativas y municipales en 1985, 1988 y 1991.

29 El Acuerdo de Esquipulas II de agosto de 1987 fue una iniciativa de los gobiernos centroamericanos para resolver las guerras en Nicaragua y El Salvador, así como el problema de la militarización de Honduras por parte de Estados Unidos. Las medidas que se adoptaron en el acuerdo incluían el cese de todo apoyo a las fuerzas irregulares por parte de los gobiernos centroamericanos. Este acuerdo fue un primer paso en la solución negociada de la crisis en Centroamérica, y sirvió de base para los acuerdos de paz en El Salvador y Guatemala.

30 Roberto Cañas, entrevista con el autor, San Salvador, 11 de agosto de 2009.

31 El propio FMLN tuvo acceso durante una buena parte de la guerra a varios representantes demócratas en la Cámara. (Eduardo Sancho, entrevista con el autor, Madrid, 29 de mayo de 2003).

32 En realidad, el adiestramiento militar de los cuadros salvadoreños se remonta al menos a 1961, cuando, como parte del Frente Unido de Acción Revolucionaria (FUAR), un grupo de militantes comunistas fueron a entrenarse a Cuba (Domingo Santacruz, entrevista con el autor, San Salvador, 3 de agosto de 2009).

33 La información al respecto aún es escasa, por lo que es difícil precisar más la fecha.

34 Según Américo Araujo, ex miembro del Comité Central del PCS (entrevista con el autor, San Salvador, 23 de agosto de 2008), pequeños contingentes de las FPL, la RN, el PRTC y el PCS combatieron junto a los sandinistas en la insurrección que puso fin a la dictadura somocista.

35 Atilio Montalvo, entrevista con el autor, San Salvador, $1^{\circ}$ de septiembre de 1998.

36 Atilio Montalvo, entrevista con el autor, San Salvador, 25 de enero de 2011.

37 Atilio Montalvo, entrevista con el autor, San Salvador, 25 de enero de 2011.

38 La Comisión Política de las FPL, basándose en una investigación inicial llevada a cabo por las fuerzas de seguridad nicaragüenses, acusó a Carpio de ser el responsable del asesinato. Dada esta imputación, y como lo indica el testimonio que dejó escrito antes de su muerte, Carpio prefirió suicidarse. La investigación del asesinato de Anaya que se condujo después, llevada a cabo por una corte de Managua, determinó que el autor intelectual de este crimen fue Rogelio Bazzaglia (Comandante Marcelo), el propio jefe de seguridad de Anaya, quien actuó por iniciativa propia, motivado por su desacuerdo con los puntos de vis- 
ta que impuso Anaya dentro de las FPL. Las verdaderas circunstancias que rodearon las muertes de Anaya y Carpio se encuentran todavía lejos de haber sido completamente esclarecidas.

39 Facundo Guardado, entrevista con el autor, San Salvador, 19 de agosto de 2008.

40 Sonia Aguiñada Carranza, entrevista con el autor, San Salvador, 11 de agosto de 2009.

41 Según los acuerdos de paz, el 20\% de los nuevos reclutas de la PNC serían ex combatientes del FMLN, otro $20 \%$ se compondría de antiguos miembros de la Policía Nacional y el $60 \%$ restante sería personal civil que no combatió durante la guerra.
42 Declaraciones de José Luis Merino, uno de los ex dirigentes del PCS y del FMLN, al periódico salvadoreño El Faro.

43 Su propuesta obtuvo el apoyo del movimiento civil "Los amigos de Mauricio”. Este es un grupo pequeño de líderes de la mediana empresa, que habían sido excluidos de los empresarios favorecidos por los gobiernos de ARENA, vinculados por lazos de amistad a Funes. El grupo estableció su propia maquinaria de propaganda electoral y su movimiento cívico ad hoc en 2008. Los "amigos" obtuvieron presencia en más de la mitad de municipios y recaudaron un monto sustancial de fondos para la campaña (Gerardo Cáceres, entrevista con el autor, San Salvador 13 de agosto de 2008). 